NBER WORKING PAPER SERIES

\title{
THE DYNAMICS OF CRIMINAL BEHAVIOR: EVIDENCE FROM WEATHER SHOCKS
}

\author{
Brian Jacob \\ Lars Lefgren \\ Enrico Moretti \\ Working Paper 10739 \\ http://www.nber.org/papers/w10739
NATIONAL BUREAU OF ECONOMIC RESEARCH
1050 Massachusetts Avenue
Cambridge, MA 02138
September 2004

We thank Alberto Abadie, Dick Butler, Joe Doyle, Steve Levitt, Lance Lochner, Erzo Luttmer, Frank McIntyre, Bruce Sacerdote and seminar participants at the 2004 NBER Summer Instittute, BYU, Wisconsin, Florida and 2004 AEA Meetings for useful suggestions. The views expressed herein are those of the author(s) and not necessarily those of the National Bureau of Economic Research.

(O2004 by Brian Jacob, Lars Lefgren, and Enrico Moretti. All rights reserved. Short sections of text, not to exceed two paragraphs, may be quoted without explicit permission provided that full credit, including $\odot$ notice, is given to the source. 
The Dynamics of Criminal Behavior: Evidence from Weather Shocks

Brian Jacob, Lars Lefgren, and Enrico Moretti

NBER Working Paper No. 10739

September 2004

JEL No. J2, K42

\begin{abstract}
$\underline{\text { ABSTRACT }}$
The persistence of criminal activity is well documented. While such serial correlation may be evidence of social interactions in the production of crime, it may also be due to the persistence of unobserved determinants of crime. Moreover, there are good reasons to believe that, particularly over a short time horizon, there may actually be a negative relationship between crime rates in a particular area due to displacement. In this paper, we exploit the correlation between weather and crime to examine the short-run dynamics of criminal behavior. Drawing on crime-level data from the FBI's National Incident-Based Reporting System, we construct a panel of weekly crime data for 116 jurisdictions. Using the plausibly exogenous variation in lagged crime rates due to unexpected weather shocks, we find that the strong positive serial correlation documented in OLS is reversed. A ten percent increase in violent crime in one week is associated with a 2.6 percent reduction in crime the following week. The corresponding reduction for property crime is 2.0 percent. Additional displacement appears to occur over a longer time horizon. Furthermore, the results do not appear to be driven by persistence in weather conditions over time or displacement of non-criminal economic activity. These findings suggest that the long-run impact of temporary crime prevention efforts may be smaller than the short-run effects.

Brian Jacob

John F. Kennedy School of Government Harvard University

79 JFK Street

Cambridge, MA 02138

and NBER

brian_jacob@harvard.edu

\author{
Enrico Moretti \\ Department of Economics \\ Evans Hall, \#3880 \\ University of California at Berkeley \\ Berkeley, CA 94720-3880 \\ and NBER \\ moretti@econ.berkeley.edu
}

Lars Lefgren

Department of Economics

Brigham Young University

130 Faculty Office Building

Provo, UT 84602-2363

1-lefgren@byu.edu 


\section{Introduction}

The persistence of criminal activity is well documented. Higher crime today in any particular area is associated with higher crime tomorrow. This serial correlation is illustrated in Figure 1. A 10 percent increase in violent crime in a typical city this week is associated with 1.6 percent more violence the following week, conditional on jurisdiction fixed effects. The serial correlation for property crime is even higher - 10 percent more property crime this week is associated with over 3.1 percent more property crime the following week. ${ }^{1}$

One of the most common explanations for this autocorrelation is that potential offenders are influenced by the criminal behavior of others - i.e., a crime committed by one individual increases the likelihood that other individuals in the same locality will engage in criminal activity. In addition to social interactions that occur over a long time-period through, for example, social learning, criminologists have long argued that forces such as imitation and revenge may lead to social multiplier or contagion effects that operate over very short time horizons such as days or weeks. ${ }^{2}$ However, the persistence in crime rates over time could also be explained by unobserved heterogeneity across localities. The persistence of unobserved factors that determine the costs and benefits of criminal activity such as police presence and poverty levels will lead to a positive correlation in crime rates over time even in the absence of a true causal relationship.

Moreover, there are good reasons to believe that, particularly over a short time horizon, there may actually be a negative relationship between crime rates in a particular area due to displacement-i.e., the shifting of criminal activity from one time or location to another. A study of juvenile curfews in Detroit, for example, found that afternoon crime nearly doubled after the introduction of the curfew (Hesseling 1994). ${ }^{3}$ More generally, the concern is that a targeted crackdown that increases police patrols in an area for one week, for example, may simply shift criminal activity to the following week.

This issue is particularly salient today given the growing consensus among criminologists and law enforcement officials on the benefits of highly targeted crime prevention strategies that focus police resources on "hot spots" and "hot times" rather than relying on more broad-based interventions. In an influential article, Sherman et. al. (1989) emphasized the importance of specific times and locations that bring together likely offenders, suitable targets and the absence of capable guardians, resulting in

\footnotetext{
${ }^{1}$ Correlation is positive for further lags. For exa mple, a 10 percent increase in violent and property crime this week is associated with 1.1 and 1.6 percent higher crime two weeks later respectively. Figure 1 is based on the analysis sample (described below) where the unit of analysis is the jurisdiction-week. The estimates come from two separate regressions of the crime rate in one week on ten lags of crime and jurisdiction fixed-effects.

${ }^{2}$ See Cook and Goss (1996) and Braga et al. (2001).

${ }^{3}$ Similarly, prior work documents that juvenile violence peaks in the after-school hours on school days and in the evenings on non-school days (Jacob and Lefgren 2003).
} 
extremely high crime rates. ${ }^{4}$ They present detailed spatial data documenting that crimes are highly concentrated in certain non-random times and locations which they refer to as "hot spots." In this and other articles, the authors argue that the existence of such "hot spots" implies that law enforcement interventions should target certain locales and time periods. This perspective - along with evidence from the criminology literature suggesting that earlier intervention strategies such as increasing the overall number of police, implementing random patrols throughout a city and arresting criminals after the commission of a crime have not been effective at reducing crime (Sherman 1997) - has led to an increased focus on targeted interventions.

Law enforcement officials, however, have long worried that the benefits of targeted crime prevention strategies may be mitigated by the temporal and spatial displacement of crime. Displacement has received considerable attention within the academic criminology literature as well, where the term is used to describe a variety of situations in which criminal activity is shifted from one time or location to another (respectively referred to as temporal or spatial displacement). ${ }^{5}$ Despite the attention it has received from both practitioners and researchers, the empirical evidence on the existence and importance of displacement remains inconclusive.

In comprehensive reviews of this literature, Eck (1993) and Hesseling (1994) conclude that there is some evidence of temporal as well as spatial displacement, but that the magnitude of such shifting is relatively small. ${ }^{6}$ Many of the studies reviewed, however, are subject to potentially serious biases since the crime prevention programs under examination are unlikely to be exogenous. Moreover, several studies find evidence of the opposite effect - that is, a diffusion of the benefits of crime reduction in one location to neighboring locations. More recent evidence on spatial displacement comes from a series of crime prevention experiments implemented in several cities. ${ }^{7}$ One such study, a randomized police patrol experiment in Minneapolis, provides some indirect evidence on temporal displacement. The intervention, which targeted increases in police presence in certain hot spots, was found to decrease disturbances,

\footnotetext{
${ }^{4}$ Sociologists refer to this theory as "routine activities theory." It was first proposed by Cohen and Felson (1979).

${ }^{5}$ Criminologists often distinguish between six distinct types of displacement, including those that involve a shift in the time (temporal displacement), location (spatial displacement), method (e.g., use of a gun versus a knife, referred to as tactical displacement), victim (target displacement), type (e.g., burglary versus robbery), or perpetrator (e.g., the crime is committed by a different individual) of a crime. See Barr and Pease (1990) for a more detailed discussion.

${ }^{6}$ The reviewers also note that the extent of displacement may differ across crime type, with drug dealing having some of the largest displacement effects and residential burglary having the smallest, although this evidence is mixed.

${ }^{7}$ In other studies, crime prevention programs were implemented in randomly chosen neighborhoods, and researchers compared changes in crime rates not only across treatment and control areas, but also across pre-defined displacement zones for both treatment and control neighborhoods. In a New Jersey experiment of the impact of an innovative drug enforcement strategy, Weisburd and Green (1995a) found some evidence of displacement for narcotics calls, but no other crime categories. In a study of problem-oriented policing on violent crime hot spots, Braga et. al. (1999) found potential displacement of property crime, but possible diffusion of benefits for disorder and assault crimes.
} 
vandalism, and fights in these areas (Sherman and Weisburd 1995). While the study did not explicitly examine displacement, Koper (1995) found that crime rates remained low in the treatment areas even during times when the police patrols were not present, which may suggest that temporal displacement was less prevalent in this intervention.

In this paper, we exploit the correlation between weather and crime to analyze the short-run dynamics of criminal activity. Our aim is to determine the true persistence of criminal activity by estimating the causal relationship between crime rates in different time periods within the same locality. In other words, we seek to answer the following question: if there is a transitory increase in the cost (benefit) of crime at time $t$, so that criminal activity at time $t$ decreases (increases), what happens to crime at time $t+1$ ? The correlation in Figure 1 would seem to imply a positive effect of crime at $t$ on crime at $t+1$, while displacement would suggest a negative effect.

Understanding the dynamics of criminal activity is of interest for both practical and theoretical reasons. If the timing of criminal behavior is more elastic to temporary changes in the costs of crime than is the total amount of criminal activity, as is the case with temporal displacement, an increase in police activity that reduces crime in a given week will result in a smaller decline in total crime committed in the long term. If this is the case, the long-run effectiveness of transitory interventions could be limited.

From a theoretical perspective, understanding the dynamics of criminal activity is important because it sheds light on the maximizing behavior of criminals. Beginning with Becker (1968), economic models of criminal behavior have generally been constructed and tested using a static framework. While these models have been very useful in understanding some features of criminal behavior, they are not well suited to explaining how criminal behavior changes over time in response to changes in various costs and benefits. The economic literature on crime dynamics is limited. ${ }^{8}$

When analyzing the effect of criminal activity at time $t$ on criminal activity at time $t+1$, the key econometric challenge is to disentangle the causal effect of crime at time $t$ from persistent unobserved heterogeneity that could induce spurious serial correlation. We use an instrumental variable strategy that is based on weather shocks. Criminologists have long recognized that weather is strongly correlated with short-run fluctuations in crime, with hotter weather generally associated with more crime and inclement weather associated with less crime. ${ }^{9}$ Given its strong impact on current period crime, weather conditions may be a plausible instrument for identifying the impact of lagged crime on current criminal activity. More specifically, we estimate models that control for a series of jurisdiction-specific seasonality

\footnotetext{
${ }^{8}$ One notable exception is Lochner (1999).

${ }^{9}$ Several channels are potentially responsible for this correlation. Psychologists have shown that higher temperatures increase aggression directly (Anderson, 1989). Alternatively, adverse weather conditions may affect the cost of executing a particular crime and/or the availability and actions of potential victims. We discuss the implications of these various channels in later sections.
} 
measures so that our identification essentially relies on deviation in expected weather patterns that influence crime rates in a particular locale.

Drawing on crime-level data from the FBI's National Incident-Based Reporting System (NIBRS), we construct a panel of weekly crime data for 116 jurisdictions from 1995-2001. Simple OLS estimates confirm that violent and property crimes are highly correlated over time within localities. Weeks with above (below) average crime rates are typically followed by weeks with above (below) average crime rates, even after controlling for a rich set of jurisdiction-specific seasonality effects.

However, when we instrument for lagged crime with lagged weather conditions, we actually find the opposite result for both property and violent crime. The 2SLS estimates reveal that weeks with above average crime rates are followed by weeks with below average crime rates. The magnitude of the displacement is substantial. A 10 percent increase in violent crime due to a weather shock reduces violent criminal activity by about 2.6 percent in the following week. We find considerable displacement for most types of crime, including simple assault, aggravated assault, violent crime by family member, violent crime with a weapon and violent crime without a weapon. Moreover, there is evidence that additional displacement occurs over a longer time horizon. The estimated reduction in violent crime over a month is 5.4 percent, more than double the estimated displacement for one week. The estimates for property crime are similar, though somewhat smaller. A 10 percent increase in property crime reduces property crime by about 2 percent the following week. Displacement of property crimes is concentrated among crimes that involve highly valuable property, like car thefts. Notably, the value of property stolen also displays significant displacement: weeks where the value of stolen property is high are followed by weeks where the value is low.

Our estimates appear quite robust. The key identifying assumption in our model is that lagged weather conditions do not directly influence current crime rates once we have conditioned on current weather. To the extent that our controls for current weather are imperfect, the persistence of weather over time may violate this exclusion restriction since lagged weather will provide some information about the unobserved component of current weather which, in turn, will directly influence current crime. To check whether this is an issue, we conduct a "reverse experiment" in which we estimate the effect of future crime on current crime using future weather conditions as our instrument. We find that, after we condition on current weather, future weather has no effect on current crime, suggesting that the persistence in weather patterns is unlikely to invalidate our identification strategy.

A second concern is that our results might be due to displacement in economic activity. If inclement weather in one period causes people to stay home, for example, it may result in greater than expected economic activity in the following period. To the extent that this increase in economic activity increases the net benefit of criminal activity (by increasing the availability of victims), we might find 
displacement in criminal activity that is unrelated to the underlying optimization of the criminal and should not be interpreted as evidence of displacement. Several pieces of evidence - including an examination of high frequency data on traffic, which we think of as a proxy for economic activity suggest that this phenomenon is unlikely to explain our results.

Overall, our analysis suggests that, in the short run, there is substantial displacement of crime over time. A simple model indicates that there are several different factors that might explain such displacement, thought they differ for property and violent crime. In the case of property crime, the existence of displacement is consistent with a model in which transitory fluctuations in the costs of crime create an income effect that is manifested for multiple periods. This dynamic is similar to the one observed in a standard labor supply model with transitory shocks in the wage. If displacement is indeed driven by intertemporal substitution, it should only operate for property crimes involving a large monetary value since the income effect of stealing small items (e.g., a candy bar) is likely to be trivial. Hence, the finding that displacement only occurs for property crimes that involve expensive gods reinforces the interpretation suggested by a labor supply framework. More generally, our findings suggest that criminal labor supply responds to transitory fluctuations in the wage in a manner that is similar to that of other self-employed individuas ${ }^{10}$ and is also consistent with evidence on the forwardlooking behavior of low-income populations. ${ }^{11}$

In the case of violent crime, the evidence is consistent with a model where the marginal utility (cost) of violence is decreasing (rising) in the amount of violence committed during the prior week. This would be true if, for example, an assailant who "settles a score" in one period feels less need to do so in a subsequent period. Similarly, a husband who abuses his wife in one period may be less inclined to do so in the next period, perhaps because of a sense of guilt or because he has received a warning from the police. $^{12}$

The finding of substantial temporal displacement contributes to the ongoing policy debate on crime prevention policies. Our estimates indicate that the long-run impact of factors that affect criminal activity (such as crime prevention programs) are likely to be smaller than the short-run impact. In contrast to what a policy-maker would infer from the simple correlation of crime over time, these results suggest that a crime delayed is not necessarily a crime prevented.

In interpreting our results, it is important to keep in mind that our estimates (like all instrumental variable estimates) reflect a particular local average treatment effect - namely the impact of an exogenous

\footnotetext{
10 See, for example, the studies of taxi drivers by Farber (2004).

${ }^{11}$ See studies of welfare recipients, for example Grogger anad Michalopoulos (2003).

12 We discuss other potential explanations below, including the role of incarceration (e.g., if offenders are incarcerated, it might be difficult to commit crimes in subsequent periods) and the physical costs of violence (e.g., injuries sustained in one period limit a perpetrator's ability to commit crime in subsequent period).
} 
increase in those crimes that are elastic to weather conditions on subsequent criminal behavior. While we believe that these results provide interesting insight regarding the dynamic optimization behavior of criminals, the relevance of our results for crime prevention policy depends on the extent to which the changes in crime due to weather shocks are similar to changes induced by police interventions.

Several factors are important to consider in this regard. First, our estimates are based off of relatively high-frequency variation, reflecting displacement that takes place over the course of several weeks up to, possibly, a few months. For this reason, our findings are unlikely to generalize to long-run crime prevention strategies such as improving the economic opportunities of youth in a community or engaging in community policing with a neighborhood over an extended period of time. On the other hand, many of the policing strategies described in the hot spot literature are relatively short-term targeted interventions and/or intermittent crackdowns that involve things such as the increased intensity of police patrols at certain times and places (see, for example, Sherman and Weisburd 1995 and Sherman 1997). These short-term strategies are becoming increasingly popular with police departments around the nation. ${ }^{13}$ Second, one might be worried that the set of criminals and/or crimes influenced by the weather may not be the same as those who would be influenced by transitory law enforcement activity. While it is impossible to reach a definitive conclusion in this regard, we show that the that weather affects a broad range of crimes, including both violent and property crime, crimes committed against strangers as well as family members, crimes committed with and without a weapon, crimes committed by juveniles as well as adults, and crimes committed indoors as well as outdoors. Finally, it is important to note that our estimates reflect changes in the cost of committing a crime that are unrelated to the probability of apprehension. For this reason, our findings are likely to generalize much better to some type of policies (e.g., visible police patrols) than others (e.g., crackdowns that involve a substantial number of arrests).

Finally, it is useful to consider how these results inform the literature on social interactions. To the extent that social interactions operate at the week-to-week frequency we examine, our estimates should be interpreted as the net effect of these social interactions and displacement. In this case, our results suggest that the total temporal displacement more than offsets social interactions operating at the weekly level. Given the relatively high frequency of our data, our estimates cannot speak to the possibility of social interactions that operate in long-run through, for example, social learning. Thus, these findings do not rule out the importance of social interactions for explaining long-run differences in crime rates across localities (for example, Glaeser, Sacerdote, Scheinkman, 1998; Kling, Ludwig and Katz, 2004). Similarly, our empirical strategy does not have the power to separately identify social

\footnotetext{
${ }^{13}$ One recent example is "Operation Neighborhood Shield" in Boston that targets troubled parks and neighborhoods for a few days at a time (New York Times, August 9, 2004). Another high-profile example was "Operation Hammer," an intervention that involved large scale temporary police sweeps in South Central Los Angels during the early 1990s.
} 
interactions operating at a very high frequency (i.e., within a week) from dsplacement. Such social interactions will tend to amplify week-to-week correlations in criminal activity caused by temporal displacement. Our estimates will thus capture the combination of displacement at the individual level and these social multipliers.

The remainder of the paper is organized as follows. Section 2 presents simple dynamic models of violent and property crime. Section 3 describes our empirical strategy and Section 4 discusses the data used in the analysis. Sections 5 and 6 present the results, and Section 7 concludes.

\section{Simple Dynamic Models of Property and Violent Crime}

In this section, we present two simple models of property and violent crime. In these models, utility maximizing criminals respond to transitory changes in the price of crime by shifting the time of their criminal activity, inducing a negative relationship between current and future crime. The goal of these models is to clarify the conditions under which temporal displacement is likely to occur. ${ }^{14}$ Because the motivations underlying violent and property crime are likely very different, we construct separate models for these two types of crime. While these models aim to highlight some of the "structural" forces that are likely to underlie our "reduced-form" estimates, we do not attempt to estimate the structural parameters of the model here.

\subsection{Property Crime}

We begin with a simple dynamic model of violent crime. Given the financial motivations underlying property crime, a standard labor supply framework provides considerable insight regarding the potential displacement of property crime. Displacement, if it occurs, would plausibly come about through an income effect-i.e., a transitory increase in the benefits of crime generates a positive income effect which reduces the incentive to commit crime in subsequent periods. This suggests that displacement will not occur when individuals are unable to borrow and save. During lucrative periods, for example, nothing is saved so the next period's choice of crime is unaffected. Likewise during lean times, offenders are unable to affect available income in subsequent periods by borrowing. This type of period-by-period maximization would also occur if individuals were completely myopic (Case 1). If, on the other extreme, criminals are far sighted and have access to good credit markets, there will also be no displacement because a transitory change in the price of criminal activity will have a negligible effect on lifetime income (Case 2). In order to generate a linkage between lagged and current criminal activity, it is

\footnotetext{
${ }^{14}$ For this reason, the models do not incorporate social interactions. Adding social interactions that operate across periods can generate persistence in criminal activity within the model. Social interactions that operate within a period will increase responsiveness to the cost factors and magnify the degree of displacement.
} 
necessary to construct a model that allows individuals to either save or borrow across periods. On the other hand, the credit market must be sufficiently imperfect or the time horizon must be short enough for a transitory shock in the benefits of criminal activity to have a meaningful income effect (Case 3). It is also important to point out that if this is the case, not all property crime is expected to experience displacement. It is unlikely that stealing a small inexpensive item could have any significant income effect. For this reason, an additional prediction of the model is that if any displacement occurs, and if it is indeed driven by an income effect, we should observe it only for crimes that involve goods with substantial monetary value. We will come back to this point in our empirical section.

We assume that an individual's utility each period is defined over consumption, $c$, and leisure, $l$, in the following way: $u_{t}=u\left(c_{t}, l_{t}\right)$. We will assume that $u\left(c_{t}, l_{t}\right)$ is increasing in both arguments and strictly concave. Each period a criminal must allocate a single unit of time between leisure and property crime, $s$. Because this time constraint must hold with equality, it must be the case that $l_{t}=1-s_{t}$. Each period, an individual earns $w_{t} s_{t}$ from criminal endeavors, where $w_{t}$ is the net wage from criminal endeavors. Note that $w_{t}$ reflects both the abundance of criminal opportunities and the period specific costs of engaging in criminal activity. In the context of our empirical analysis, fluctuations in the weather generate variation in $w_{t}$-perhaps due to weather related changes in the supply of targets or in the disutility of committing crime outdoors. ${ }^{15}$

Case 1: The first case worth discussing is one in which individuals are unable or unwilling to save or borrow. An example would be individuals with severe substance abuse problems who have exhausted informal borrowing channels and spend all available funds each period. In this case, the agent faces the following budget constraint: $c_{t} \leq w_{t} s_{t}$ each period. We assume that the criminal maximizes discounted lifetime utility subject to the budget constraints he faces.

It is trivial to show that the first order conditions are equivalent to those obtained from the periodby-period maximization problem. This is because each period's utility and budget constraint is unaffected by that which has gone before or that which will occur later. For this reason, a transitory shock to the benefit (wage) of property crime can have no impact beyond the current period. More intuitively, during lucrative periods nothing is saved so the next period's choice of crime is unaffected. Likewise during lean times, offenders are unable to affect available income in subsequent periods by borrowing.

Case 2: Another extreme case is that criminals are farsighted and have access to perfect capital markets. While it is unlikely that most offenders have access to sophisticated capital markets, this case is

\footnotetext{
${ }^{15}$ Similar results could be obtained by assuming that weather affects the utility cost of engaging in criminal activity.
} 
not completely unrealistic and it may still be useful as a benchmark. Criminals may save money without the aid of a financial institution and may also be able to borrow from friends and family.

Abstracting from uncertainty, each offender chooses a series of consumption and criminal activity to maximize his lifetime utility. The Lagrangian for the offender's optimization problem is:

$$
\max _{\left\{c_{0}, \ldots\right\},\left\{s_{0}, \ldots\right\}, \lambda} \sum_{t=0}^{T}\left(\frac{1}{1+\rho}\right)^{t} u\left(c_{t}, 1-s_{t}\right)+\lambda\left(\sum_{t=0}^{T}\left(\frac{1}{1+r}\right)^{t} w_{t} s_{t}-\sum_{t=0}^{T}\left(\frac{1}{1+r}\right)^{t} c_{t}\right) .
$$

where $r$ is the interest rate at which an offender can borrow or lend, and $T$ is the number of periods and is assumed to be large. In order to understand how a transitory change in the wage of crime affects subsequent criminal behavior, it is helpful to examine the first order conditions:

$$
\begin{aligned}
& \left(\frac{1}{1+\rho}\right)^{t} \frac{\partial u\left(c_{t}, 1-s_{t}\right)}{\partial c_{t}}-\lambda\left(\frac{1}{1+r}\right)^{t}=0, \\
& -\left(\frac{1}{1+\rho}\right)^{t} \frac{\partial u\left(c_{t}, 1-s_{t}\right)}{\partial l_{t}}+\lambda\left(\frac{w_{t}}{1+r}\right)^{t}=0
\end{aligned}
$$

together with the budget constraint. Equations 2 and 3 must hold for all $t$. It is now no longer true that the first order conditions are equivalent to those consistent with period-by-period optimization. Instead, the ability to borrow and save implies that the marginal utility of lifetime income, $\lambda$, is a function of the wages of crime in every period. Thus while an increase in $w_{t}$ can induce a substitution effect that causes $s_{t}$ to rise, the only mechanism through which it can affect $s_{t+1}$ is through $\lambda$. This corresponds to an income effect. In dynamic models of labor supply, it is generally assumed that the lifetime income effects of a transitory wage shock are minimal. ${ }^{16}$

What happens to property crime if the cost of first period crime exogenously increases? If the effect of a transitory change in $w_{t}$ has only a minimal effect on lifetime income, we would not expect this shock to substantively affect later criminal behavior. In other words, exactly like in Case 1, if the credit markets work sufficiently well, we might observe little temporal displacement of criminal activity.

Case 3: Consider a model identical to the one above except with $T=2$. For simplicity, assume that the discount rate and the interest rate are both zero and the utility function is separable in consumption and leisure. Under these assumptions, the first order conditions are identical to those in equations (2) and (3). What happens to crime at time 2 when there is an exogenous shock to the net benefit of committing crime in period 1 ? The comparative statics are straightforward:

\footnotetext{
${ }^{16}$ In fact, labor supply elasticities identified off of high-frequency variation in the wage are referred to as lambdaconstant labor supply elasticities.
} 


$$
\frac{d s_{2}}{d w_{1}}=-\frac{w_{2}}{\frac{\partial^{2} u_{2}}{\partial l_{2}^{2}}} \frac{d \lambda}{d w_{1}}<0
$$

where $d ? / \mathrm{dw}_{1}<0$ and the number in the subscript denotes the time period. ${ }^{17}$ Equation 4 indicates that an increase in the first period wage of crime will reduce the amount of criminal activity committed in period 2. This occurs because a transitory increase in the benefits of crime generates a positive income effect (lowering the marginal utility of wealth) which reduces the incentive to commit crime in subsequent periods. Assuming that the substitution effect dominates the income effect in the first period, ${ }^{18}$ a transitory increase in the wage of crime will initially lead to higher levels of crime and will then reduce subsequent criminal activity. In this case, we will observe temporal displacement of property crime.

Taken together, these three simple cases help us understand in which cases we expect temporal displacement to occur and provide a framework with which to interpret our empirical findings. In particular, a finding of no displacement is consistent with complete myopia, an inability to borrow or save, or good credit markets and farsighted criminals. On the other hand, finding displacement is consistent with short term fluctuations in the crime wage generating a meaningful income effect that lasts beyond the current period. This would occur if criminals chose consumption and criminal activity to maximize utility over a limited time horizon (it could also occur in a model with sufficiently imperfect credit markets). Although not directly modeled, incarceration may in theory be an additional factor behind the displacement. However, given the low arrest and conviction rates, in our empirical analysis below we argue that it is unlikely that incarceration could explain a substantial portion of the displacement observed in our context.

${ }^{17}$ Note that the effect of an increase the wage of period 1 crime on the amount of criminal activity in period 1 is ambiguous: $\frac{d s_{1}}{d w_{1}}=-\frac{\lambda}{\frac{\partial^{2} u_{1}}{\partial l_{1}^{2}}}-\frac{w_{1}}{\frac{\partial^{2} u_{1}}{\partial l_{1}^{2}}} \frac{d \lambda}{d w_{1}}$. The first term of this expression is the substitution effect and is positive; the second term captures the income effect and is negative. It is not obvious which effect would dominate. Also, note that

$\frac{d \lambda}{d w_{1}}=-\frac{\frac{\partial^{2} u_{1}}{\partial c_{1}^{2}} \frac{\partial^{2} u_{2}}{\partial c_{2}^{2}} \frac{\partial^{2} u_{2}}{\partial l_{2}^{2}}\left(w_{1} \lambda-\frac{\partial^{2} u_{1}}{\partial l_{1}^{2}} s_{1}\right)}{\Delta}<0$. To see that it is negative, consider that $\Delta$ is the determinant of the bordered hessian matrix and must be negative in order for the second order conditions to hold.

${ }^{18}$ If we thought of the amount of property crime as the dollars generated from criminal activity, $w_{t} s_{t}$, the amount criminal activity in period 1 necessarily increases. In other words, the amount stolen would rise- even if the amount of time spent on criminal activity declined. In this case, a rise in the period 1 wage of crime would increase period 1 crime and reduce period 2 crime. This would lead to the temporal displacement of property crime. 


\subsection{Violent Crime}

The motives underlying violent crime tend to be much different than those underlying most property crime. For this reason, we provide a separate theoretical framework with which to analyze the dynamics of violent crime. In our model, temporal displacement may occur for two reasons. First, the benefits of violence may persist over time. This would be true if injuring an individual in the first period "settled a score" or "taught a lesson," reducing the need to do so again in the second period. Second, the costs of violence in one period may in theory depend on the level of violence in the previous period, which may be the case if a violent act in the first period resulted in arrest and/or greater police supervision in the second period. A simple two period model illustrates these points with a minimum of complexity.

Assume that first period utility is given by the following:

$$
u_{1}=g_{1}\left(v_{1}\right)-\theta_{1} v_{1}
$$

where $v_{1}$ is violence in the first period, $g_{1}\left(v_{1}\right)$ is an increasing but concave function of $v_{1}$ and $\theta_{1}$ is an exogenous per-unit cost of violence. Second period utility is given by the following:

$$
u_{2}=g_{2}\left(v_{2}+\delta v_{1}\right)-\theta_{2}\left(v_{1}\right) v_{2},
$$

where $v_{2}$ is violence in period $2, \delta$ is the fraction of the benefits of violence that carry over to the next period, $g_{2}\left(v_{2}+\delta v_{1}\right)$ is an increasing and concave function and $\theta_{2}\left(v_{1}\right)$ is the per-unit cost of committing violence in the second period. ${ }^{19}$

In our model, the per-unit cost of violence in the second period, $\theta_{2}\left(v_{1}\right)$, is an increasing and convex function of first period violence. This is likely to be true for several reasons. Violent acts in the first period may result in arrest or increased police supervision; injuries sustained in the first period could hamper the ability to commit violent crime in the second period; or, for crimes such as domestic violence, it is possible that guilt over a violent act in period 1 would increase the cost of committing a similar act in period 2.

The criminal's optimization problem involves choosing period 1 and 2 violence to maximize utility over the two periods. The first order conditions of this problem are the following:

$$
\frac{\partial U\left(v_{1}, v_{2}\right)}{\partial v_{1}}=\frac{d g_{1}\left(v_{1}\right)}{d v_{1}}-\theta_{1}+\delta \frac{\partial g_{2}\left(v_{2}+\delta v_{1}\right)}{\partial v_{2}}-\frac{d \theta_{2}\left(v_{1}\right)}{d v_{1}} v_{2}=0 \text { and }
$$

\footnotetext{
19 This cost represents both the expected physical and psychic costs of committing a violent act as well as the possibility of legal sanctions. We do not assume that the cost of second period violence is a function of the average level of violence in period 1. This assumption precludes a police enforcement response to a temporary increase in crime. Given that our empirical specification will be identified off of small variations in criminal activity, we don't feel that this assumption is very costly.
} 


$$
\frac{\partial U\left(v_{1}, v_{2}\right)}{\partial v_{2}}=\frac{\partial g_{2}\left(v_{2}+\delta v_{1}\right)}{\partial v_{2}}-\theta_{2}\left(v_{1}\right)=0 .
$$

These conditions define the equilibrium level of crime in the two periods. ${ }^{20}$

What happens to violent crime if the cost of first period violence exogenously increases (for example because of a weather shock)? It is not surprising that that an increase in first period violence results in a decrease in violent crime in the first period: $\frac{d v_{1}}{d \theta_{1}}<0 .{ }^{21}$ The comparative static for second period crime is more relevant for our analysis. In particular, what happens to violent crime in period 2 when there is an exogenous shift in the cost of violent crime in period 1 ?

$$
\frac{d v_{2}}{d \theta_{1}}=\frac{-\delta \frac{\partial^{2} g_{2}}{\partial v_{2}^{2}}+\frac{d \theta_{2}}{d v_{1}}}{\Delta}>0
$$

The denominator of (9) must be positive in order for the second order conditions to hold. Both terms in the numerator are positive suggesting that second period violence is likely to increase in the first period cost of violence if either the benefits of violence are durable $(\delta>0)$ or the marginal cost of second period violence is rising in first period violence. These findings suggest that the displacement of violent crime can occur under plausible conditions.

\section{Empirical Strategy}

The previous section suggests that crime in one period may affect crime in the next period either positively or negatively. The basic empirical framework therefore relies upon estimating the following simple equation:

$$
\text { crime }_{i, t}=\beta_{0}+\beta_{1} \text { crime }_{i, t-1}+\varepsilon_{i t} .
$$

where crime $_{i, t}$ reflects the level of crime in jurisdiction $i$ in period $t$ and $\beta_{1}$ reflects the causal effect of an exogenous increase in criminal activity on the next period's crime. Following the models presented in Section 3, $\beta_{1}$ is the net effect of social interactions and displacement. The empirical challenge is that crime $_{i, t-1}$ is almost certainly positively correlated to the error term $\varepsilon_{i t}$, since factors affecting the costs

20 Note that these conditions take into account that $\frac{g_{2}\left(v_{2}+\delta v_{1}\right)}{\partial v_{1}}=\delta \frac{\partial g_{2}\left(v_{2}+\delta v_{1}\right)}{\partial v_{2}}$.

21 In particular, $\frac{d v_{1}}{d \theta_{1}}=\frac{\frac{\partial^{2} g_{2}}{\partial v_{2}^{2}}}{\Delta}$ where ? is the determinant of the matrix of second order conditions and must be positive in order for the second order conditions to hold. 
and benefits of crime are likely persistent over time. For example, a local crime prevention effort may last for a number of weeks. In this case, conventional OLS estimates of the parameter $\beta_{1}$ will be biased upward relative to the true causal effect.

\subsection{Identification}

In order to identify the causal impact of lagged criminal activity, it is necessary to identify an instrument that is correlated with criminal activity in period $t$-1 but uncorrelated to the error term. One candidate instrument is the weather. The correlation between criminal activity and weather conditions has been well documented. ${ }^{22}$ It has been hypothesized that higher temperatures might increase aggression directly (see Anderson, 1989), thus providing a transitory increase in the net benefit of criminal activity. Adverse weather conditions may affect the cost of executing a particular crime, due to changes in the ease of transportation or the likelihood of witnesses to the crime which may influence the chance of arrest.

In this model, the second stage is given by:

$$
\text { crime }_{i t}=\mathrm{B} X_{i t}+\beta_{1} \text { crime }_{i, t-1}+\beta_{2} \text { weather }_{i t}+\varepsilon_{i t}
$$

where $i$ indexes jurisdictions and $t$ indexes time period (in our analysis, a week), $X_{i t}$ is a vector of control variables and weather $_{i t}$ is a vector of weather variables. The first stage is given by:

$$
\text { crime }_{i, t-1}=\Gamma X_{i t}+\gamma_{1} \text { weather }_{i, t-1}+\gamma_{2} \text { weather }_{i t}+\eta_{i t}
$$

The key identifying assumption in this model is that, conditional on weather at time $t$ and other covariates, weather at time $t-1$ cannot directly influence crime at time $t$. More formally, $\operatorname{cov}\left(\varepsilon_{i t}\right.$, weather $r_{t-1} \mid$ weather $\left.r_{t}, X_{i t}\right)=0$. Because weather may vary across cities and years in a way that is correlated with crime rates, our controls include jurisdiction*year fixed effects. Similarly, to account for the seasonality of crime patterns that are unrelated to weather, we include jurisdiction-specific fourth order polynomials in day-of-year. ${ }^{23}$ To control for common seasonality-related factors such as summer breaks and holidays, we include fixed effects for each month (which do not vary by jurisdiction). Even with this rich set of covariates, one might be concerned that the persistence of weather conditions over

\footnotetext{
22 See Cohn's (1990) extensive literature review on the subject. More recent work on the issue by Rotton and Cohn (2000) and Field (1992) confirms the finding.

${ }^{23}$ We choose not to control for seasonality using fixed effects to avoid the bias associated with lagged dependent variables in fixed effects models. The magnitude of this bias is inversely related to the number of periods per fixed effect. In the setup we use, this is unlikely to be a problem as we use weekly data with city*year fixed effects.
} 
time within a locality, along with imperfect measures of weather, could lead to a violation of our identifying assumption. We discuss this in greater detail below. ${ }^{24}$

To increase the efficiency of our estimates, we weight each observation by the average number of (violent or property) crimes committed each day in the jurisdiction. ${ }^{25}$ The standard errors are cluster corrected (Moulton, 1986) at the state*year*month level as weather and criminal activity may be spatially and temporally correlated. In some models we include more than one lag in crime. We use the same strategy to examine the impact of crime from more distant period. In particular, when equation (11) includes crime at $t-1, t-2, t-3$ and $t-4$, we instrument $t-2$ crime using $t-2$ weather conditions, $t-3$ crime using $t-3$ weather conditions, and so forth.

\subsection{Threats to Identification and Interpretation}

In assessing our research design, it is important to highlight several potential issues. A first concern is that weather, when measured at high frequency, is serially correlated. If temperature today is high, for example, it is likely that temperature tomorrow will also be high. Therefore, in the absence of good controls for current weather, lagged weather may be directly correlated with current crime because it will contain information regarding current weather. While we do control for current weather conditions in our models, it is possible that weather within a period is measured imperfectly, in which case lagged weather may still provide information regarding the unobserved aspects of current weather. For example, one day's maximum temperature likely provide information regarding the weather conditions at 1 a.m. of the next day. The combination of serial correlation in weather, along with imperfect measures of weather conditions in any one period, will violate the assumptions necessary for satisfactory identification and result in a positive bias in the coefficient on lagged crime.

However, as we formally demonstrate in Appendix A, this bias decreases as the length of the time window expands. To test the presence of such bias, we conduct a "reverse experiment" where we estimate the effect of future crime on current crime, and instrument for future crime with future weather. Specifically, we estimate a specification in which the dependent variable is crime in period $t$, but the right-hand-side variable is crime in period $t+1$ and the instrument is weather conditions in period $t+1$. If measurement error in weather conditions is an important source of bias, the bias would be similar whether

\footnotetext{
24 One might be concerned that this instrumenting strategy does not work since the first stage seems inconsistent with the recursive structure of the data-generating process. However, it is trivial to show that, if the exclusion restriction holds, our strategy yields an unbiased estimate of $\beta_{1}$.

${ }^{25}$ Jurisdictions frequently overlap, making it difficult to use population as a weight. For example, the jurisdiction of the Utah County Sheriff's Department includes the jurisdiction of the Provo City Police Department. The effective population monitored by the sheriff's department is much smaller than the entire population of the county. Note that this does not affect the reporting of crimes - that is, the same crime will not appear multiple times in our data.
} 
we look at lagged or future crime. Thus, we would expect the estimated impact of future crime on current crime to be positive and statistically significant.

Empirically, we find that this type of bias is indeed a problem when we use narrow time windows ( 1 or 3 days), but it ceases to be a problem once we control for seasonality and use sufficiently long time periods (a week or longer). We find that when we use weekly variation, the estimated impact of future crime is not significantly different from zero for either violent or property crime (see Section 7). This suggests that by using the weekly crime rate as the unit of analysis throughout the paper, we minimize any bias that arises from the persistence of weather conditions.

A second concern is that weather may affect the intensity of non-criminal activities, and therefore may directly affect the benefits of crime. For example, if weather affects the number of shoppers in a shopping mall, the opportunities for car theft at the mall may also be affected. ${ }^{26}$ Specifically, our identification strategy might yield biased estimates if (1) weather conditions affect the cost of some noncriminal activities; and (2) the marginal utility of these non-criminal activities depends on the amount of activity in the preceding period (these two conditions imply that weather displaces non-criminal activity); and (3) the amount of these non-criminal activities affects the benefits/costs of criminal activity.

To assess whether empirically this is an important source of bias, we examine three pieces of evidence. To begin, we provide evidence regarding the extent to which some non-criminal activities are displaced by weather conditions. We were able to find high frequency data on traffic, which we regard as a proxy for the overall level of non-criminal activity. Although traffic is correlated with current weather, we find little evidence that it is affected by lagged weather in a way that would bias our crime models. Analysis of attendance patterns at major league baseball games yields a similar conclusion. Second, we examine the impact of lagged crime on indoor and outdoor crimes separately. The type of weather conditions that reduce violent and property crime are those generally associated with reductions in outdoor activity (i.e. colder temperatures and precipitation). If there is displacement in non-criminal behavior, we would expect to see more outdoor activity after a bad spell of weather. If crime follows economic activity, we should also expect more outdoor crime following bad weather (and vice versa) but less indoor crime. This suggests that our displacement results would be focused on outdoor as opposed to indoor crime. We find no evidence of differential displacement depending on the location of the crime. A third source of evidence regarding the potential bias from the displacement of economic activity comes from results that focus on the relationship between offenders and victims for violent crime. It seems plausible that interactions with family members would be least sensitive to the degree of economic activity, yet we find significant displacement effects for violence against family members. Taken

\footnotetext{
${ }^{26}$ Cohen and Felson (1979) propose that the incidence of crime is largely determined by the availability and actions of potential victims.
} 
together, these three pieces of evidence indicate that our finding of temporal displacement is unlikely to be driven only by non-criminal economic activity.

Finally, in interpreting our estimates it is important to realize that our strategy yields a particular local average treatment effect, LATE (Imbens and Angrist 1994). The estimates presented here reflect the impact of an exogenous increase in those crimes that are elastic to weather conditions. We will provide evidence in Section 6 that weather affects a broad range of criminal behaviors. It is possible, however, that the set of criminals whose behavior is affected by the weather is very different from the set of criminals who vary their behavior in response to transitory law enforcement activity. Thus, while our findings are suggestive, they might not fully generalize to other contexts.

\section{Data}

Crime data are from the FBI's National Incident Based Reporting System (NIBRS). The unit of observation in NIBRS is a particular criminal incident. Because of the richness of the information available for each crime, the NIBRS is particularly well suited to study high frequency determinants of crime in general and temporal displacement in particular. NIBRS reports information on the date, time, and nature of each reported crime. It also reports information on the characteristics of the victim and perpetrator. This allows us to aggregate the data into categories and time periods of our choosing. ${ }^{27}$ Because the most severe crimes occur infrequently in the jurisdictions that we observe, we focus our analysis on broad aggregates such as violent and property crime. Violent crimes include simple and aggravated assault, intimidation, homicide, manslaughter, and sex crimes. Property crimes include extortion, counterfeiting, fraud, larceny, vehicle theft, robbery, and stolen property offenses. ${ }^{28}$

Data on weather are from the National Climatic Data Center (NCDC). They contain daily readings of minimum and maximum temperature, and inches of precipitation for 24,833 weather stations in the United States. We average these weather measures across stations within each county to construct a county-level panel of daily weather conditions. ${ }^{29}$ As discussed in Section 4, we aggregate the daily data

\footnotetext{
${ }^{27}$ In some jurisdictions, multiple days in a single month contain no criminal activity due to misreporting by the police agency. In these cases, we restrict the sample in following manner. We drop jurisdiction-month observations in which the monthly crime rate is more than twice the jurisdiction-specific interquartile range below the median. We use the monthly crime rate because in some jurisdictions, it might be the case that no crime occurred over several days or weeks. By using a longer time period, we are more confident that we are excluding observations with gross underreporting. We choose to restrict the sample on the basis of median and interquartile range because these measures are less sensitive to periodic massive underreporting than are the mean and standard deviation. However, if monthly crime is normally distributed, our exclusion restriction corresponds to months in which criminal activity is more than 2.67 standard deviations below the mean.

${ }^{28}$ Robbery is included as a property crime because the underlying motive is financial. Vandalism is excluded for the same reason.

${ }_{29}$ During the sample period, some weather stations moved a short distance. The location used is the average longitude and latitude over the period the weather station was operating. A small number of jurisdictions are in
} 
for both crime and weather to the weekly level in order to reduce any bias due to the autocorrelation of weather.

Our primary analysis sample includes 116 jurisdictions for the period 1995-2001 with a total of 26,338 jurisdiction-week observations. ${ }^{30}$ In order to maximize the statistical power of our estimates, we have chosen the largest jurisdictions for which NIBRS data is available. While NIBRS is by no means a nationally representative sample of police jurisdictions in the U.S., and the largest jurisdictions in the country tend not to participate, our sample does include a relatively diverse set of cities and counties. (For a complete list of the jurisdictions included in our sample, see Table A1.) For example, the jurisdictions in our sample span 17 states, with 5 percent of jurisdictions from the Northeast, 32 percent from the Midwest, 63 percent from the South, and 18 percent from the West. The five jurisdictions in our sample with the largest number of crimes reported are Chattanooga, TN, Cincinnati, OH, Austin, TX, Nashville, TN, and Memphis, TN. The jurisdictions with the five smallest number of crime reported are Rock Hill, SC, Iowa City, IA, Burlington, VT, Riley County, and Pocatello, ID.

Because some jurisdictions are larger than others, it is helpful to normalize the crime rate across jurisdictions to avoid problems due to heteroskedasticity. This is often done by using the natural log of the crime rate. This specification is not well suited for the current paper because, when examining specific types of crimes, it is often the case that no crimes occur during the course of a given week. Because our identification strategy involves a two-stage least squares approach, count-models are also not particularly useful. Thus, in our primary specifications our measure of criminal activity is the number of crimes committed during the week divided by the average weekly incidence in the jurisdiction during the sample period. $^{31}$ In Section 6, we examine the robustness of our results to this functional form assumption.

Tables 1 and 2 show summary statistics for our sample. Table 1 shows the weekly incidence of selected crimes in our jurisdictions. All of the means are calculated weighting each jurisdiction by the average number of weekly crimes in the jurisdiction. On average, about 93 violent crimes are reported each week in our jurisdictions; 56 of these are simple assault (e.g. violence not involving a weapon or serious injury), and 17 are aggravated assault. In about 70 percent of cases, the victim knows the offender-indeed about 23 percent of all violence is between family members. Property crime is more common than violent crime with nearly 240 reported incidents per week. About 60 percent of these incidents involve larceny of some type. Other types of property crime are far less common. In Table 2,

counties without weather stations. For these jurisdictions we use the weather data from an adjacent county. Because minimum temperature and maximum temperature are fairly collinear, we use the average of the two instead of both.

${ }^{30}$ Models with more than one lag generally have slightly fewer observations because of missing weather and/or crime data.

${ }^{31}$ Recall that defining the appropriate population measure is complicated by the fact that jurisdictions overlap. 
we are able to see the distribution of weather conditions in our sample. The mean weekly temperature in our sample is 58 degrees Fahrenheit. In the average week, there is only 0.11 inches of daily precipitation. In the 18 percent of weeks that experience some snowfall, there is an average of 0.40 daily inches of snowfall. Note that a number of jurisdictions appeared to be somewhat inconsistent in reporting snowfall. For this reason, we include only measures of temperature and precipitation in our preferred specifications, though our estimates are robust to the inclusion and use of snowfall.

\section{Main Empirical Findings}

We now turn to our empirical results. In this section, we present the key results from our base specification. In the next section, we present several pieces of evidence intended to validate our identification strategy and to probe the robustness of our estimates.

\subsection{Graphical Relationship between Lagged and Current Crime}

Figures 2 and 3 illustrate the baseline serial correlation of crime in our data. To do so, we regress the violent or property crime rate in period $t$ on ten lags of crime within the same jurisdiction, controlling for the same set of covariates that will be used in our primary estimation - namely, jurisdiction*year fixed effects, jurisdiction-specific fourth order polynomials in day of year as a smooth control for seasonality, month fixed effects, and average temperature and total precipitation in period $t$ as controls for current weather conditions. Standard errors are clustered by state-year-month to account for spatial and temporal correlation. The figures present the coefficients on all lagged crime variables. They differ from Figure 1 in the set of controls.

Figure 2 shows that violence during each of the past five weeks is a significant predictor of violence in the current period. The coefficients on the lags start at 0.065 and generally fall with distance from the reference week. By week six, the coefficients are statistically insignificant. In Figure 2, we see that the serial correlation for property crime is even higher than that for violent crime (e.g., the coefficient on the first lag is 0.22 ), but the autocorrelation appears to decay in a similar way. ${ }^{32}$ While these conditional correlations are statistically significant, it is interesting to note that they are smaller than the unconditional correlations presented in Figure 1. For example, the unconditional property crime estimates suggest that a 10 percent increase in crime is associated with a 3.2 percent increase the following week whereas the conditional estimates suggest only a 2.2 percent increase. This suggests that factors associated with jurisdiction-specific time and jurisdiction-specific seasonality effects (e.g., factors

\footnotetext{
32 Property crime may exhibit more persistence for at least two reasons. First, unobserved factors affecting the attractiveness of criminal activity may be more persistent for property than for violent crime. Second, since property crime is more common than violent crime, lagged property crime is a more precise proxy of unobserved cost factors than is lagged violent crime. It therefore suffers from less attenuation bias.
} 
such as seasonal changes in the economy, or police interventions) have a strong influence on crime rates. To the extent that other unobserved cost factors are also persistent but fail to follow a seasonal trend, even these estimates are likely to overstate the dynamic consequences of a transitory change to the price of crime.

\subsection{The Effect of Weather on Crime}

Criminologists have long recognized that weather has a powerful influence on criminal activity, suggesting it might serve as a plausible instrument to identify the relationship between crime rates over time. Here we examine the relationship between weather and crime in our data.

Table 3 examines the relationship between weather and violent as well as property crime using the baseline set of controls described above. ${ }^{33}$ The dependent variable here is the number of incidents in a jurisdiction-week divided by the average number of weekly incidents in that jurisdiction over the entire sample period, so that the coefficients on the explanatory variables can be interpreted roughly as a percent change in the outcome. ${ }^{34}$ Looking first at columns $1-4$, we see that weather - particularly temperature - is strongly correlated with violent crime. Column 1 indicates that a ten degree increase in the average weekly temperature is correlated with about a 5 percent increase in criminal activity. Precipitation, on the other hand, is associated with reductions in criminal activity. An increase in average weekly precipitation of 1 inch is associated with a 10 percent reduction in violence. These effects are highly significant—the F-statistic of joint significance is over 200.

Columns 2-4 show the results of several alternative specifications. In column 2, we see that while snowfall has a significant negative effect on violent crime, it does not appreciably increase the explanatory power of the model. Column 3 indicates that there is a convex relationship between temperature and crime-very hot temperatures result in a more than proportional increase in violencebut a concave relationship between precipitation and violence. Column 4 presents the results of an even more flexible specification that yields roughly the same results. Compared with a week in which the average daily temperature was less than 10 degrees each day, for example, a week in which the average temperature every day was between 50 and 60 degrees would have roughly 20 percent more violent crime. A week in which the temperature every day was above 90 degrees would experience 36 percent more crime.

\footnotetext{
${ }^{33}$ Note that this is not exactly equal to our first stage. Our first stage, described in equation (12), is the regression of crime at time $\mathrm{t}-1$ on weather at time $\mathrm{t}$ and weather at time $\mathrm{t}-1$. Here, our goal is to show what is the effect of weather on simultaneous crime.

${ }^{34}$ Recall that we scale the outcome to account for heterogeneity and we use the average number of incidents rather than a population measure because population is not readily available for the county jurisdictions in our sample.
} 
We see similar patterns for property crime, although weather appears to be less predictive of property than violent crime. Column 5 indicates that as the average weekly temperature rises by 10 degrees, property crimes fall by about 3 percent. The coefficient on precipitation is not statistically significant. Column 6 shows that snowfall (as well as snow cover) is associated with less property crime. The F-statistic of joint significance for all weather variables is 51, quite high but not as large as the corresponding statistic for violent crime. Given these results, in our main estimates we will use linear measures of temperature and precipitation to instrument for lagged crime. Later, we show that our results are robust to alternative specifications.

Table 4 shows the effect of temperature and precipitation on a variety of different types of crimes. This not only provides additional insight regarding the overall weather-crime relationship but, perhaps more importantly, allows one to better interpret the local average treatment effect of the estimates presented below. The results in Table 4 indicate that the effect of weather is quite consistent across all types of violent crime. Weather has a similar effect on domestic violence and violence against strangers; across crimes of varying levels of seriousness; regardless of whether a weapon was used; and for violent crimes involving juvenile as well as adult offenders. The results for various types of property crimes are roughly similar-higher temperature is always associated with more property crime-although the effect of precipitation varies more for property than violent crime. ${ }^{35}$

\subsection{The Effect of Heat Waves on Crime}

Our instrumental variables analysis exploits the correlation between weather and crime to provide exogenous variation in criminal activity which we use to identify the true persistence of crime over time. Here we illustrate the intuition behind this strategy using an example of extreme weather conditionsheat waves. We identify a set of unusually hot weeks that were followed by relatively normal weather. ${ }^{36}$ If displacement occurs, we should see relatively high crime during the hot week and relatively low crime during the subsequent weeks.

Figure 4 shows the results for violent crime. The solid line shows average temperature during the hot week (time 0) along with the temperature during the subsequent ten weeks. The dashed line shows how the average deviation of the violent crime rate from the predicted rate. In week 0 , both temperature and violent crime are higher than expected. Indeed, the violent crime rate is 4.5 percentage

\footnotetext{
${ }^{35}$ Higher precipitation appears to be associated with increases in the incidence of burglary. We speculate that precipitation may reduce the probability of detection, perhaps because there are fewer people around to serve as potential witnesses or there is reduced visibility.

${ }^{36} \mathrm{We}$ define unusually hot weeks as those in which the average weekly temperature is 6 degrees Fahrenheit warmer than predicted after controlling for jurisdiction-year fixed effects and jurisdiction-specific fourth order polynomials in day of year. To be included in our sample, the temperature of the following week must be within 3 degrees of the predicted temperature. There are 1,108 such weeks in our sample.
} 
points higher than normal. The following week, temperature is close to its predicted value. Violent crime, however, is nearly 2 percentage points lower than normal, suggesting displacement of about 40 percent over the subsequent week. Over the next ten weeks, both temperature and the rate of violent crime bounce around the predicted level, though violent crime is unusually high eight weeks after the hot week. Figure 5 shows the analogous results for property crime. During the initial hot week, property crime is more than 2 percentage points higher than expected. The following week it is about .5 percentage points lower. This is again consistent with displacement, though the drop in week 1 is smaller than for violent crime. In the subsequent weeks, we again see a small amount of variation around the predicted crime rate.

The analysis of heat waves - an extreme weather shock - casts doubt on the positive serial correlation of crime that one observes in the raw data (Figure 1), suggesting that it may reflect persistency in unobserved determinants of crime rather than social interactions or other behavioral phenomena. Indeed, these results indicate that, over a short-time horizon, exogenous increases in crime may be followed by decreases in crime-suggesting temporal displacement in criminal activity. In the next subsection, we present IV estimates that take advantage of all of our data and utilize variation in precipitation as well as temperature.

\subsection{Estimates of the Impact of Lagged Crime on Current Criminal Activity}

Tables 5 and 6 present OLS and IV estimates of the relationship between lagged and current crime. By way of reminder, the first and second stage specifications are given by equations (11) and (12) respectively. As explained above, all models include jurisdiction*year fixed effects, month effects and the jurisdiction-specific fourth-order polynomials in day-of-year to control for seasonality. In order to account for the persistence of weather over time, they also control for current weather conditions including the weekly average of daily mean temperature, inches of precipitation. Our instruments are lagged average temperature and total precipitation. ${ }^{37}$ To take into account that the error terms are not independent across jurisdictions or over time, we cluster the standard errors at the state*year*month level. $^{38}$

Looking first at the violent crime results in Table 5, we see the strong positive correlation documented in Figures 2 and 3. The OLS coefficients indicate that weeks with above (below) average criminal activity are followed by weeks that also have above (below) average criminal activity. However,

\footnotetext{
${ }^{37}$ We do not use snowfall due to concerns about the consistency of data collection. Our estimates are robust to the inclusion of snowfall measures.

${ }^{38}$ In theory, one limitation of this type of clustering is that we allow for arbitrary autocorrelation between two weeks in the same month, state and year, but not between two weeks in different months, even if they are consecutive weeks. We assume that this is not a major problem in our context. We have experimented with different clustering, including ones that include shorter and longer periods, and found our standard errors to be robust.
} 
when we instrument for lagged violent crime using lagged weather conditions, the results are actually reversed. The IV estimate in column 2, for example, indicates that a 10 percent increase in criminal activity in one week is associated with a 2.6 percent decrease the following week. Note that the first stage F-statistic is 213, indicating that our instruments are quite strong (which is also reflected in the precision of our estimates). In columns 4, 6 and 8 , we see that the effects of more distant lags are generally smaller than the first lag, though most estimates remain significant and negative. The sum of the lags provides a measure of the total displacement over an extended period of time. For example, in column 8 , the sum of the four lags is -0.536 , indicating that a 10 percent increase in violent crime during a particular week is associated with a reduction of roughly 5.4 percent over a one-month period - roughly double our estimate for the one-week period. Note that the magnitude of the implied displacement is quite large. For example, these results suggest that the actual impact of a violent crime prevention program is less than half the magnitude of its contemporaneous impact.

The results for property crime in Table 6 reveal a similar pattern. In stark contrast to the positive correlations documented in OLS, the IV estimates suggest that lagged crime has a significant negative effect on crime in the current period. The estimate in column 2, for example, indicates that a 10 percent increase in property crime in one week will lead to a 2.0 percent decline in property crime the following week. Note that, like in violent crime, the IV estimates are not only significantly different than zero, but also significantly different than the OLS estimates. In all models, the sum of the lags is negative and significantly different than zero. The effects are somewhat smaller for property than violent crime, but are still substantial. In column 8 , the sum of the four lagged crime measures is -0.33 , which implies that for property crime, the displacement that occurs over one month is roughly 50 percent more than that which occurs over one week.

To this point, we have examined up to four lags. However, it is possible that displacement could operate over an even longer time horizon. To examine this possibility, we calculate IV estimate for both violent and property crime in which we include up to ten lags and present the results in Figures 6 and 7. Note that these results are directly comparable to the OLS estimates shown in Figures 2 and 3. Figure 6 shows the results for violent crime. As we saw earlier, the first, second, and fourth lags are significantly different from zero. The others hover around zero but are not consistently of one sign or another. At -0.37 , the sum of the ten lags is negative and significant at the 10 percent level suggesting that all of the displacement in violent crime occurs within a month. Figure 7 shows the results for property crime. In contrast to the results we found earlier, none of the lags is statistically different from zero. Furthermore, the sum of lags is only -0.14 and statistically insignificant. Though the point estimates suggest that little displacement occurs over 10 weeks for property crime, the standard error on the sum of coefficients is too 
large to rule out substantial displacement. For both violent and property crime, however, the results do stand in stark contrast to the positive OLS estimates.

\subsection{Estimates by Specific Crime Categories}

It is of great interest to establish how our results vary by type of offense. This is complicated by the fact that temporal displacement may occur across different types of crime. For example, an aggravated assault that is prevented by adverse weather conditions may result in a simple assault in a later period. $^{39}$ For this reason, a regression of simple assault on lagged simple assault may violate the assumptions necessary for valid instrumental variables identification. In particular, the instruments (lagged temperature and precipitation) may influence simple assault in the current period not only through its effect on lagged simple assault, but also through its effect on lagged aggravated assault or some other type of related crime in the prior period. To overcome this issue, when examining the effect of lagged crime on particular types of crime, we estimate models in which the left-hand-side variable is the rate of the specific type of crime under examination while the right-hand-side variable is a lagged measure of all violent or property crime. ${ }^{40}$

Table 7 shows the findings for violent crime. The results suggest that an exogenous increase in violent crime leads to subsequent reductions in most violent crime categories. In particular, a 10 percent increase in all violent crime reduces simple and aggravated assaults by 3.5 and 2.9 percent respectively. Similarly, a 10 percent increase in all violent crime reduces violent crime against family members and individuals known to the offender by nearly 3.0 percent over one week. We see similar effects for crimes with and without weapons. In all cases, when examining a four-lag model, we observe substantial displacement for all types of violent crime. ${ }^{41}$ While our specification allows us to examine whether or not displacement occurs for particular crimes, it is not possible to compare the magnitudes of the coefficients across crime types. Still, these models allow us to conclude that temporal displacement of violence appears to operate for a variety of different types of violent crime.

In Table 8, we examine the findings for different types of property crime. Remember that the simple labor supply framework outlined in Section 2 predicts that displacement should only operate for property crimes involving a fairly large monetary value, since the predicted income effect of stealing small items (e.g., a candy bar) is likely trivial. Consistent with that prediction, the point estimates for the

\footnotetext{
${ }^{39}$ In practice, the difference between simple and aggravated assault can be fairly small. Indeed, relatively minor differences in the seriousness of injury can lead to a different categorization.

${ }^{40}$ Note that these models assume that there is no displacement from violent to property crime, or vice versa. While this is probably not strictly true, it is likely that the magnitude of this type of displacement is second-order. Estimates from models where the right-hand-side is the specific crime under consideration are available upon request. In general, they are qualitatively similar to the ones shown here.

41 These estimates are computed from separate regressions in which we include one or four lags.
} 
IV results suggest substantial displacement only for burglary and vehicle theft, although only the effects for vehicle theft are statistically significant. Because many property crimes - particularly those in the categories of larceny, shoplifting or robbery - involve relatively small amounts of money, it is not surprising that we find little effect for these crimes.

To more accurately capture property crime displacement, we estimate a model in which we measure property crime by the total value of the property stolen during a particular period. ${ }^{42}$ Interestingly, the results in column 7 indicate significant displacement over a one-week period. A 10 percent increase in the value of property stolen in one week is associated with a decline in value of property stolen in the following week by nearly 6 percent. The results for the four-lag model are not precise enough to be informative. Overall, these results for property crime suggest some displacement over a short time period, although the results are not as robust as for violent crime.

\section{Threats to Identification and Robustness Checks}

In this section, we present several pieces of evidence intended to investigate the validity of our identification strategy and to probe the robustness of our estimates. We begin in subsection 6.1 by investigating whether the temporal displacement of non-criminal economic activity may invalidate our instrument. In subsection 6.2 we assess whether persistence in weather conditions coupled with imperfect measurement are an important source of bias. In subsection 6.3, we present robustness checks from a variety of alternative specifications as well as separate estimates for specific subsamples.

\subsection{Temporal Displacement of Non-Criminal Economic Activity}

The main identifying assumption in our empirical strategy is that lagged weather conditions only influence current period crime through their influence on lagged crime. While high frequency variation in weather is unlikely to be correlated with many of the unobserved factors that determine the persistence of crime over time (e.g., income levels, crime prevention policies, etc.), weather may affect the intensity of non-criminal activity which, in turn, could influence the cost and/or benefit of crime. If inclement weather causes people to stay home in one period for example, it may result in greater than expected economic activity in the following period, which could increase the benefits of crime (by, for example, increasing the availability of victims). More generally, if weather displaces non-criminal activity and this activity influences the cost/benefit of criminal activity, our estimates may be biased.

To assess the empirical importance of this concern, we first provide evidence regarding the extent to which non-criminal activity is displaced by weather conditions. Though few measures of economic

\footnotetext{
${ }^{42}$ As with the other models, we normalize by diving by the average for the jurisdiction over the entire sample period. We obtain comparable results if we use the log of the total value of stolen property.
} 
activity are reported at a sufficiently high frequency to examine this issue, we have collected information from the Federal Highway Administration (FHWA) that includes daily measures of traffic from in-road monitors in over 20,000 locations throughout the United States for 2000-2001. We regard traffic as a good summary measure for non-criminal economic activity. ${ }^{43}$ We aggregate this data to the county-week level, so that our primary outcome measure is the number of vehicles counted in a particular county during a given week. ${ }^{44}$

Table 9 shows the results of specifications that are analogous to the primary crime specifications shown in Tables 5 and 6. The OLS estimates in column 1 indicate that an increase in traffic one period is associated with a 62 percent increase in traffic in the following period. In results not presented here, we find that weather affects traffic volume in the expected direction - higher temperatures are associated with more traffic while precipitation is associated with less traffic - but that the predictive power of these weather variables is relatively low, with an F-stat on the first stage is only 8.62. This is extremely informative itself since if weather does not have a strong impact on this type of economic activity over a one-week period, it is unlikely that weather would induce substantial amounts of displacement to bias our estimates.

When we instrument using the weather conditions, we find zero relationship between traffic in period $t-1$ and period $t$. While zero displacement of economic activity may seem odd at first, it is important to keep in mind that the specifications presented here capture displacement over a one-week period. The displacement in economic activity that involves driving is likely to take place over a shorter time period. For example, one may well postpone going to the grocery store on any particular day because of rain, but is then likely to make the trip within the next day or two. It is also important to remember that, like we did for the baseline crime models, we are controlling for current weather conditions. When we look at the four-lag specifications in columns 3-4, there is again no significant relationship between prior and current traffic volume, although the estimates are not very precise.

While the point estimates shown above suggest that weather shocks lead to little if any displacement in traffic over one-week interval, the large standard errors do not allow us to rule out substantial displacement. To obtain more precise estimates, we estimate our models on a larger sample

\footnotetext{
${ }^{43}$ The traffic volume data includes hourly traffic counts for each traffic station provided by permanent in-road traffic monitors. Geographic identifiers allow one to link each station to states and counties. Traffic data is available for 66 of the 92 counties included in the crime analysis. Recall that our primary analysis sample for crime includes 116 jurisdictions in 92 counties in 17 states. For more information on the traffic data, see: Office of Highway Policy Information at http://www.fhwa.dot.gov/policy/ohpi.

${ }^{44}$ To be consistent with the crime estimates, we normalize these measures by dividing weekly counts by the average for that county over the sample period.
} 
that includes all of the counties in the 17 states in our crime sample that had traffic data. ${ }^{45}$ The results are presented in columns 5-8. As with the more limited sample, there is no evidence of displacement. If anything, the IV estimates suggest modest, marginally significant positive effects of prior traffic on current traffic. As a second measure on non-criminal activities, we were able to find data on attendance at Major League Baseball games. We found little evidence of displacement in attendance. ${ }^{46}$

As a second piece of suggestive evidence on temporal displacement in economic activity, we estimate separate models for indoor and outdoor crime. If weather induces displacement in non-criminal activity, we would expect to see more (less) outdoor activity after a bad (good) spell of weather. If crime follows economic activity, we should also expect more outdoor crime following bad weather (and vice versa) but less indoor crime. This suggests that our displacement results would be focused on outdoor as opposed to indoor crime. In specification 2 of Table 10, we regress the rate of indoor crime on the rate of all crime. ${ }^{48}$ We do the same for outdoor crime in specification 3. For violent crime, an exogenous increase in violent crime leads to significant reductions in both outdoor and indoor violence over a fourweek period, although the one-week effect is only significant for indoor crime. The property crime estimates are uniformly negative and similar in magnitude for indoor and outdoor crime, but only significantly different from zero in one of four cases (i.e., for indoor crime only over a one-week period).

A third suggestive piece of evidence regarding the potential bias from the displacement of economic activity can be obtained by examining the relationship between offenders and victims for violent crime. It seems plausible that interactions with family members would be least sensitive to the degree of non-criminal economic activity. In Table 7, we showed that an exogenous increase in violent crime leads to statistically significant reductions in the amount of violence against family members during

\footnotetext{
${ }^{45}$ The large number of counties prohibit running the identical specification. With 570 counties in the 17 states, a model that includes jurisdiction-year fixed effects and jurisdiction-specific 4th order polynomials in day-of-year would require nearly 3,500 covariates. We therefore estimate a more parsimonious model that includes main effects for jurisdiction and year (instead of effects for jurisdiction-year) and state (instead of jurisdiction) specific seasonality controls. We note that in the baseline sample (that used in columns 1-4), the parsimonious specification yields results comparable to the original model. Tables are available from the authors upon request.

${ }^{46}$ Data are for each Major League Baseball game between 1980 and 1999. We aggregate attendance at the weekly level, and estimates models that are similar to the ones used for crime and traffic. When we regress attendance in one week on attendance in the previous week, the OLS coefficient is -.330 (.018). However, the corresponding IV estimate is virtually zero. We conclude that there is little evidence of displacement in major league baseball attendance.

${ }^{47}$ These results are reassuring, although ideally, one would like to look at a broader set of measures of economic activity to draw more general conclusions. A recent paper looks at the effect of weather on retail sales (StarrMcCluer, 2000). The author finds some evidence of displacement. Unusually cold temperatures in a given month tend to depress sales in that month, but they lead to higher sales in the following month. The current and lagged effects do not completely offset each other. Moreover, unusually warm weather is a given month increases sales, but reduces sales in the month after. The current and lagged effects roughly offset each other. Unfortunately, data on retail sales are available only at the monthly level, which makes the comparison with our analysis difficult.

${ }^{48}$ This specification is appropriate given that displacement could occur across venues.
} 
the following week. Although by no means definitive, taken together these results suggest that our finding of temporal displacement is not driven by displacement of non-criminal economic activity.

\subsection{Persiste nce in Weather}

A second concern is that weather, when measured at high frequency, is serially correlated. While we control for current weather conditions in our models, it is possible that weather within a period is measured imperfectly, in which case lagged weather may still provide information regarding the unobserved aspects of current weather which would, in turn, directly impact current crime. As discussed earlier, this will violate the assumptions necessary for satisfactory identification and result in a positive bias in the coefficient on lagged crime. In Appendix A, we formally demonstrate that this bias decreases as the length of the time window expands. For this reason, we aggregate to the weekly level.

To examine whether this source of bias is empirically unimportant in our current framework, we conduct a "reverse experiment" where we estimate the effect of future crime on current crime, and instrument for future crime with future weather. Specifically, we estimate a specification in which the dependent variable is crime in period $t$, but the right-hand-side variable is crime in period $t+1$ and the instrument is weather conditions in period $t+1$. If measurement error in weather conditions is an important source of bias, the bias would be similar whether we look at lagged or future crime. Thus, we would expect the estimated impact of future crime on current crime to be positive and statistically significant. In specification 4 of Table 10, we see that this is not the case. In particular, the estimated impact of future crime is small in magnitude and statistically insignificant for both violent and property crime. This suggests that our results are not materially affected by imperfect weather measures.

\subsection{Robustness Checks and Heterogeneity of Effects}

Table 10 presents the results from a variety of alternative specifications. Row 5 indicates that our results are comparable if we measure crime using the log number of violent or property crimes rather than scaling by the average number of crimes in the jurisdiction. ${ }^{49}$ Rows 6-8 present estimates using three alternative sets of instruments - only temperature, only precipitation and, finally, temperature, precipitation, snowfall, and snow cover. ${ }^{50}$ The results using only temperature and all four weather variables (rows 6 and 8) are nearly identical to our baseline specification. When we limit our instruments to precipitation alone, we have very little statistical power, particularly in the case of property crime. The

\footnotetext{
${ }^{49}$ This is equivalent to a specification in which we use log crime rates given our use of jurisdiction*year fixed effects.

${ }^{50}$ In specifications 6 and 7, we control for both current period temperature and precipitation as well as lagged temperature (precipitation) in order to ensure that that the only variation in lagged precipitation (temperature) is used to identify the impact of lagged criminal activity. In specification 8, we control for current period measures of all four weather variables.
} 
four-lag violent crime results are comparable to baseline, though the one-lag results show no displacement.

In our primary specification, we implicitly assume symmetry between the effect of an exogenous reduction in criminal activity and an exogenous increase in criminal activity. However, this need not be the case. For example, individuals prevented from committing a criminal act may do so in a subsequent period while individuals who engage in opportunistic crimes due to favorable weather conditions may not reduce their criminal activity during the following week. We investigate potential asymmetry in specification 9 and 10. To examine the impact of positive weather shocks, we construct a variable that is the average temperature during a week if the temperature was above the average in the state during the month and zero otherwise. We use this as our only instrument in the first stage. To examine the impact of negative shocks, we do the analogous analysis using variation in temperature below the average. Over a one-week period, the displacement results appear to be larger for positive shocks than negative shocks. Over four weeks, however, the displacement effects appear roughly consistent across positive and negative shocks.

Table 11 presents estimates for several subgroups. Row 2 suggests that the displacement operates over a longer time-period for juvenile offenders - the one-week lag is roughly half the size of the baseline while sum of four lags is actually somewhat larger than the baseline. Rows 3 and 4 separately examine city and county jurisdictions. ${ }^{51}$ The point estimates suggest that there is substantially less displacement in county jurisdictions, particularly for property crime, although the standard errors for the county estimates are quite large. Rows 5 to 8 present the results separately by region of the country. While the standard errors are fairly large for these estimates, there appears to be substantial displacement of violent crime across regions. The property crime results are even less precise, though there is some evidence that there is less displacement in the West and Midwest. Finally, in rows 9 to 12, we present separate estimates by season. For violent crime models with one lag, we find the largest effect in the spring and summer. Results for property crime are not very precise, and preclude meaningful inference.

\section{Conclusion}

In this paper, we exploit the correlation between weather and crime to examine the short-run dynamics of criminal activity. In sharp contrast to the positive serial correlation in crime rates reported in most studies, we find that higher crime in one week is followed by less crime in subsequent weeks. The results do not appear to be driven by persistence in weather conditions over time or displacement of noncriminal economic activity, and are robust to a variety of alternative specifications. These findings suggest that the positive serial correlation in crime commonly reported is not an endogenous process

\footnotetext{
${ }^{51}$ The county jurisdictions in NIBRS are primarily county sheriffs' departments.
} 
driven by the optimization of offenders, but likely reflects persistence of unobserved factors that influence of criminal activity.

The magnitude of displacement in violent and property crime over a short-time horizon is substantial. A 10 percent increase in violent crime in one week leads to a 2.6 percent reduction in violent crime the following week. Over the course of four weeks, over half of the initial increase in violence will be mitigated through displacement. Displacement occurs across a wide variety of violent crimes, including simple as well as aggravated assault, violence against family members as well as strangers, crimes committed against strangers, crimes committed with and without weapons, and crimes committed by juvenile offenders. The results for property crime are somewhat smaller-a 10 percent increase in property crime results in a decrease of 2.0 percent the following week — and appear to be limited to high value property crimes, vehicle theft in particular.

These results are important both for theoretical and policy reasons. First, they shed light on the optimization behavior of criminals in a dynamic setting, a topic on which existing evidence is limited. In the case of property crime, our results indicate that criminal behavior is consistent with a standard labor supply framework. Within this framework, the observed displacement can be explained by an income effect. Criminals who are prevented from committing property offenses in a given week engage in higher levels of criminal activity during the subsequent weeks to make up for lost income. This behavior is consistent with a model in which offenders have at least some foresight and/or are some liquidity constraints. Our findings cannot be rationalized in a context of permanent-income offenders who face no liquidity constraints and have very long time horizons. Notably, we find that displacement arises only for crimes that involve highly valuable property which lends further support to the notion that displacement is driven by an income effect.

In the case of violent crime, a possible interpretation of the results is that the benefits of violence may be durable - i.e., the marginal utility (cost) of violence is decreasing (rising) in the amount of violence committed during the prior week. This would be true if, for example, an assailant who "settles a score" in one period feels less need to do so in a subsequent period. Similarly, a husband who abuses his wife in one period may be less inclined to do so in the next period, perhaps because of a sense of guilt or because he has received a warning from the police. ${ }^{52}$

Incarceration may in theory be a factor behind the displacement of property and violent crime. However, given the low arrest and conviction rates, it is unlikely that incarceration could explain a substantial portion of the observed displacement. Consider, for example, that each incident of violence

\footnotetext{
${ }^{52}$ An alternative interpretation is that the physical costs of a violent act to an assailant might increase the costs of violence in subsequent periods. Since simple assaults comprise the majority of violent crimes, it seems unlikely that a large portion of violent crimes cause serious injury to the offender. By definition, simple assault does not involve serious injury to the victim, let alone the offender.
} 
reported produces only about .4 arrests. $^{53}$ It is likely that at least half of these are either not charged with an offense or released almost immediately on bail. ${ }^{54}$ Furthermore, even if the remaining individuals are involved in a reported act of violence 10 times per year, incarceration could only generate displacement of about 4 percent over one week, a small fraction of the total effect. ${ }^{55}$ This is even truer for property crime, where clearance rates are much lower. ${ }^{56}$

Besides its theoretical implications, the uncovering of substantial temporal displacement may also have important policy implications. Our findings suggest that the long-run impact of temporary crime prevention efforts may be smaller than the short-run effects. ${ }^{57}$ In the case of violent crime, the short run impact of a one week crime prevention effort will be twice as large as the impact over one month. For property crime, the immediate effect is likely to overstate by half a longer-run measure of crime prevention. To the extent that policy makers engage in short-term policy experiments or anti-crime crackdowns, standard policy evaluations may prove misleading.

It should be noted, however, that the estimates presented here reflect a particular local average treatment effect - namely, the impact of lagged crime that is elastic to weather conditions. The relevance of our results for policy depends upon the extent to which the set of criminals and crimes whose behavior is affected by the weather is similar to the sets which respond to transitory law enforcement activity. Although we show that weather affects a broad range of criminal behaviors, it is important to recognize that our findings might not fully generalize to other contexts, particularly those that involve longer-term interventions such as improving economic opportunities for potential offenders or short-run interventions that involve the incapacitation of many potential offenders. In addition, because of the high frequency variation of our data, the estimates presented here speak to short-run criminal dynamics. It is still possible that important social interactions occur over a longer time period so, for example, our results do not rule out the importance of social interactions for explaining long-run differences in crime rates across localities.

In conclusion, this paper sheds new light on the intertemporal behavior of criminals. Our findings suggest that transitory changes in the costs of crime lead to the temporal displacement of criminal activity. We provide an economic framework that rationalizes these findings in the context of

\footnotetext{
${ }^{53}$ This was computed using 2000 NIBRS data for the jurisdictions in our sample.

54 DiIulio (1996) reports that of 641,000 individuals arrested for violent crimes in 1992, only 165,000 were convicted of a crime, suggesting that this estimate may be conservative.

55 This is computed by multiplying .4 arrests per incident *.5 individuals in custody per arrest $* .2$ crimes committed per week.

${ }^{56}$ A related possibility is that the cost being caught is an increasing and convex function of the number of crimes committed. Because we are looking at week-to-week variation in crime rates, we suspect that in our context, this is not empirically very relevant. For most crimes, it is unlikely that offenders are caught, arrested, tried sentenced and freed in one week.

${ }^{57}$ On the other hand, the results also suggest that a transitory lapse in law enforcement is not likely to spiral into an extended crime wave.
} 
offenders maximizing utility in a dynamic context. We show that understanding displacement is important in evaluating the effects of short-term policy interventions. Despite these contributions, additional work is likely to be helpful in further understanding crime dynamics. Possibly fruitful avenues of future research include examining temporal displacement using variation in specific law enforcement activities. 


\section{References}

Anderson, Craig A. "Heat and Violence." Current Directions in Psychological Science. (2001): 33-38.

Anderson, Craig A., Anderson, Kathryn B., Dorr, Nancy, DeNeve, Kristina M., and Flanagan, Mindy. "Temperature and Aggression." Advances in Experimental Social Psychology, 32 (2002): 63133.

Barr, Robert and Pease, Ken. "Crime Placement, Displacement and Deflection." In Michael Tonry and Norval Morris (Eds.) Crime and Justice: A Review of Research 12. Chicago: University of Chicago Press, 1990.

Becker, Gary. "Crime and Punishment: An Economic Approach." Journal of Political Economy 76, no. 2 (1968): 169-217.

Braga, Anthony A., Weisburd, David L., Waring, Elin J., Mazerolle, Lorraine G., Spelman, William, and Gejewski, Francis. "Problem-Oriented Policing in Violent Crime Places: A Randomized Controlled Experiment." Criminology 37, no. 3 (1999): 541-580.

Braga, Anthony A., Kennedy, David M., Waring, Elin J., and Piehl, Anne M. "Problem-Oriented Policing, Deterrence and Youth Violence: An Evaluation of Boston's Operation Ceasefire." The Journal of Research in Crime and Delinquency (forthcoming).

Camerer, Babcock, Lowenstien and Thaler "Labor Supply of New York City Cab Drivers: One Day at the Time." Quarterly Journal of Economics (1997): 407-411.

Cohn, Ellen G. "Weather and Crime." British Journal of Criminology.Vol. 30, No. 1 (Winter 1990): 5164.

Cohn, Ellen G. and Rotton, James. (2000). "Weather, Seasonal Trends and Property Crimes in Minneapolis, 1987-88: A Moderator-Variable Time-Series Analysis of Routine Activities." Journal of Environmental Psychology 20 (2000): 257-272.

Cook, Philip J. and Goss, Kristin A “A Selective Review of the SocialContagion Literature." Working paper. Raleigh: Duke University, 1996..

DiIulio, John J. “A New Crime Wave.” Investor’s Business Daily, March 6, 1996.

Eck, John E. “The Threat of Crime Displacement.” Criminal Justice Abstracts 25 (1993): 527-546.

Farber, Henry "Is Tomorrow Another Day? The Labor Supply of New York City Cab Drivers", Princeton (2003).

Field, Simon. "The Effect of Temperature on Crime." British Journal of Criminology. Vol. 32 no. 3 (Summer 1992): 340-351.

Glaeser, Edward L., Sacerdote, Bruce, and Scheinkman, Jose A. "Crime and Social Interactions." The Quarterly Journal of Economics 111, no. 2 (1996): 507-548. 
Grogger, Jeffrey and Michalopoulos, Charles. "Welfare Dynamics under Time Limits." Journal of Political Economy. 111, no. 3 (2003): 530-554.

Hesseling, Rene B. P. "Displacement: A Review of the Empirical Literature." In Clarke, R.V. (Ed.), Crime Prevention Studies (vol. 2). Monsey, NY: Criminal Justice Press, 1994.

Jacob, Brian A. and Lefgren, Lars. "Are Idle Hands the Devil's Workshop? Incapacitation, Concentration and Juvenile Crime." American Economic Review. 93, no. 5 (2003): 1560-1577.

Kling, Jeff, Ludwig, and Katz, Lawrence. "Youth Criminal Behavior in the Moving To Opportunity Experiment." Working paper, Princeton University, 2004.

Kopoer, Christopher. "Just enough police presence: Reducing crime and disorderly behavior by optimizing patrol time in crime hot spots." Justice Quarterly 12 (1995): 649-672.

Lochner, Lance. "Education, Work and Crime: Theory and Evidence" (1999).

Rotton, James and Cohn, Ellen G. "Violence Is a Curvilinear Function of Temperature in Dallas: A Replication." Journal of Personality and Social Psychology 78, no. 6 (2000): 1074-1081.

Sherman, Lawrence W. "Fair and Effective Policing." In Wilson, James Q. Wilson and Joan Petersilia, Joan (Eds.), Crime: Public Policies for Crime Control. Oakland, CA: ICS Press, 2002.

Sherman, Lawrence W., Patrick R. Gartin, and Michael E. Buerger, "Hot Spots of Predatory Crime: Routine Activities and the Criminology of Place." Criminology 27: 27-55 (1989).

Sherman, Lawrence W. and Weisburd, David. "General Deterrent Effects of Police Patrol in Crime 'Hot Spots': A Randomized, Controlled Trial.” Justice Quarterly 12 (1995): 625-48.

Sherman, Lawrence W., Gottfredson, Denise C., MacKenzie, Doris L., Eck, John, Reuter, Peter, and Bushway, Shawn D. Preventing Crime: What works, what doesn't, what's promising. Washington, DC: National Institute of Justice, US Department of Justice, 1997.

Sah, Raj. "Social Osmosis and Patterns of Crime." Journal of Political Economy 99 (1991): 1272-95.

Starr-McCluer, Martha, The Effects of Weather on Retail Sales. Federal Reserve Board Discussion Series, 2000.

Weisburd, David and Green, Lorraine. "Policing Drug Hot Spots: The Jersey City Drug Market Analysis Experiment." Justice Quarterly 12, no. 4 (1995): 711-735. 


\section{Appendix A}

In this appendix we prove that aggregation reduces the bias associated with measurement error in weather conditions. To see this, assume that crime is generated by the following process:

(A1) $c_{t}=\beta w_{t}+\varepsilon_{t}$,

where $c_{t}$ is the crime rate, $w_{t}$ denotes weather conditions, and $\varepsilon_{t}$ is a mean zero i.i.d. residual. The subscript indicates the time period. For simplicity, we will assume that all variables have been demeaned. $w_{t}$ is assumed to have a finite variance, $\sigma_{w}^{2}$. This entails no loss of generality but allows us to ignore the constant. We assume that weather is measured with error in the following way:

(A2) $\hat{w}_{t}=w_{t}+v_{t}$,

where $\hat{w}_{t}$ is the observed weather conditions and $v_{t}$ is a mean zero error term with variance $\sigma_{v}^{2}$. Weather conditions evolve according to an $\mathrm{AR}(1)$ process that is described by the equation below.

(A3) $w_{t}=\rho w_{t-1}+\eta_{t}$

Given this process, we can examine the bias that occurs when estimating the following empirical specification.

$$
c_{t}=a_{0} \hat{w}_{t}+a_{1} c_{t-1}+e_{t} .
$$

Following the approach described in the body of this paper, this equation can be estimated using lagged observed weather conditions to instrument for lagged crime. Because we have a single instrument and a single variable to instrument, the system is exactly identified. Thus the instrumental variables (IV) of $a_{0}$ and $a_{1}$ are given by the following:

(A5) $\left[\begin{array}{l}a_{0} \\ a_{1}\end{array}\right]=\left(Z^{\prime} X\right)^{-1} Z^{\prime} Y$,

where

$$
\begin{aligned}
& Z=\left[\begin{array}{cc}
\hat{w}_{t} & \hat{w}_{t-1} \\
\hat{w}_{t-1} & \hat{w}_{t-2} \\
\cdot & \cdot
\end{array}\right], \\
& X=\left[\begin{array}{cc}
\hat{w}_{t} & c_{t-1} \\
\hat{w}_{t-1} & c_{t-2} \\
\cdot & \cdot
\end{array}\right], \text { and }
\end{aligned}
$$




$$
Y=\left[\begin{array}{c}
\beta w_{t}+\varepsilon_{t} \\
\beta w_{t-1}+\varepsilon_{t-1} \\
\cdot
\end{array}\right]
$$

Relying on the law of large numbers and Slutsky's theorem and noting that $\operatorname{cov}\left(\hat{w}_{t}, \hat{w}_{t-n}\right)=\rho^{n} \sigma_{w}^{2}$, $\operatorname{var}\left(\hat{w}_{t}\right)=\sigma_{w}^{2}+\sigma_{v}^{2}$, and $\operatorname{cov}\left(c_{t}, \hat{w}_{t-n}\right)=\beta \rho^{n} \sigma_{w}^{2}$, it is easy to show that:

$$
p \lim \left[\left(Z^{\prime} X\right)^{-1} Z^{\prime} Y\right]=\left[\begin{array}{cc}
\sigma_{w}^{2}+\sigma_{v}^{2} & \beta \rho \sigma_{w}^{2} \\
\rho \sigma_{w}^{2} & \beta \sigma_{w}^{2}
\end{array}\right]^{-1}\left[\begin{array}{c}
\beta \sigma_{w}^{2} \\
\beta \rho \sigma_{w}^{2}
\end{array}\right] .
$$

Performing the appropriate matrix algebra, we find that:

$$
p \lim \left(a_{1}^{I V}\right)=\frac{\rho \sigma_{v}^{2}}{\left(1-\rho^{2}\right) \sigma_{w}^{2}+\sigma_{v}^{2}}>0 .
$$

Even though lagged crime has no causal effect on current crime. This proof shows that the IV estimate will converge to a positive number. It is trivial to see that this is only the case when weather is autocorrelated over time and weather is measured with error. When this is true, the lagged measures of weather conditions provide information about current conditions and are thus correlated with the current level of criminal activity. This correlation does not operate through the lagged crime rate; thus, the IV estimate of lagged criminal activity is inconsistent.

Aggregating over several periods reduces the magnitude of this bias. We will now prove that this is the case. To do so, we will assume that the data generating process described by equations A1 to A4 still hold. If these conditions are satisfied, the following relationship will hold as well.

(A11) $c_{t+1}+c_{t}=\beta\left(w_{t+1}+w_{t}\right)+\varepsilon_{t+1}+\varepsilon_{t}$.

Note that if instead of summing over two periods we took the average of all variables, the results would be identical. The algebra is slightly less cumbersome using sums, however, so we will proceed in that fashion. Though the data generation process is characterized by equation A11, the empirical specification we will consider is given by:

$$
c_{t+1}+c_{t}=a_{0}\left(\hat{w}_{t+1}+\hat{w}_{t}\right)+a_{1}\left(c_{t-1}+c_{t-2}\right)+e_{t+1}+e_{t} .
$$

We again consider the estimation of this specification using IV where we instrument $c_{t-1}+c_{t-2}$ using $\hat{w}_{t-1}+\hat{w}_{t-2}$. The estimator is defined by equation (A5) but

$$
Z=\left[\begin{array}{cc}
\hat{w}_{t+1}+\hat{w}_{t} & \hat{w}_{t-1}+\hat{w}_{t-2} \\
\hat{w}_{t-1}+\hat{w}_{t-2} & \hat{w}_{t-3}+\hat{w}_{t-4} \\
\cdot & \cdot
\end{array}\right],
$$


(A14) $X=\left[\begin{array}{cc}\hat{w}_{t+1}+\hat{w}_{t} & c_{t-1}+c_{t-2} \\ \hat{w}_{t-1}+\hat{w}_{t-2} & c_{t-3}+c_{t-4} \\ \cdot & \cdot\end{array}\right]$, and

(A15) $Y=\left[\begin{array}{c}\beta\left(w_{t+1}+w_{t}\right)+\varepsilon_{t+1}+\varepsilon_{t} \\ \beta\left(w_{t-1}+w_{t-2}\right)+\varepsilon_{t-1}+\varepsilon_{t-2} \\ \cdot\end{array}\right]$.

It is again straightforward to show that the IV estimator converges to the following:

(A16) $p \lim \left[\left(Z^{\prime} X\right)^{-1} Z^{\prime} Y\right]=\left[\begin{array}{cc}2(1+\rho) \sigma_{w}^{2}+2 \sigma_{v}^{2} & \beta \rho(1+\rho)^{2} \sigma_{w}^{2} \\ \rho(1+\rho)^{2} \sigma_{w}^{2} & 2 \beta(1+\rho) \sigma_{w}^{2}\end{array}\right]^{-1}\left[\begin{array}{c}2 \beta(1+\rho) \sigma_{w}^{2} \\ \beta \rho(1+\rho)^{2} \sigma_{w}^{2}\end{array}\right]$

Again, straightforward matrix algebra shows that:

(A17) $p \lim \left(a_{1}^{I V_{-} a g g}\right)=\frac{\rho \sigma_{v}^{2}}{2 \sigma_{w}^{2}-\frac{\rho\left(1-\rho^{2}\right) \sigma_{w}^{2}}{2}+\frac{2 \sigma_{v}^{2}}{1+\rho}}>0$.

It is trivial to show that when $\rho<1$ (this is necessary for the measure of weather conditions to have a finite variance), the bias associated with the 2 period aggregate specifications is smaller than the bias from a 1 period specification. 
Table 1: The Incidence of Criminal Activity

\begin{tabular}{|c|c|c|c|}
\hline \multicolumn{2}{|c|}{ Violent Crimes } & \multicolumn{2}{|c|}{ Property Crimes } \\
\hline & $\begin{array}{c}\text { Weekly } \\
\text { Frequency }\end{array}$ & & $\begin{array}{c}\text { Weekly } \\
\text { Frequency }\end{array}$ \\
\hline All Violent Crimes & $\begin{array}{c}92.05 \\
(110.36)\end{array}$ & All Property Crimes & $\begin{array}{l}238.86 \\
(278.77)\end{array}$ \\
\hline Simple Assault & $\begin{array}{l}56.59 \\
(65.71)\end{array}$ & Larceny & $\begin{array}{c}144.32 \\
(155.54)\end{array}$ \\
\hline Aggravated Assault & $\begin{array}{c}15.79 \\
(22.85)\end{array}$ & Shoplifting & $\begin{array}{c}21.83 \\
(27.11)\end{array}$ \\
\hline $\begin{array}{l}\text { Offender's Relationship to } \\
\text { Victim }\end{array}$ & & Burglary & $\begin{array}{c}43.08 \\
(58.95)\end{array}$ \\
\hline Family Member & $\begin{array}{c}26.57 \\
(30.30)\end{array}$ & Robbery & $\begin{array}{c}9.48 \\
(16.52)\end{array}$ \\
\hline $\begin{array}{l}\text { Family Member, Friend, or } \\
\text { Acquaintance }\end{array}$ & $\begin{array}{l}71.33 \\
(87.46)\end{array}$ & Vehicle Theft & $\begin{array}{c}23.35 \\
(35.09)\end{array}$ \\
\hline Stranger & $\begin{array}{c}16.86 \\
(20.07)\end{array}$ & & \\
\hline \multicolumn{4}{|l|}{ Weapon Use } \\
\hline With Weapon & $\begin{array}{c}20.84 \\
(29.66)\end{array}$ & & \\
\hline No Weapon & $\begin{array}{c}71.21 \\
(83.87)\end{array}$ & & \\
\hline With Gun & $\begin{array}{c}4.46 \\
(9.25)\end{array}$ & & \\
\hline Location & & Location & \\
\hline Inside & $\begin{array}{c}69.04 \\
(86.08)\end{array}$ & Inside & $\begin{array}{c}159.64 \\
(181.92)\end{array}$ \\
\hline Outside & $\begin{array}{l}17.70 \\
(21.20)\end{array}$ & Outside & $\begin{array}{c}62.37 \\
(92.69)\end{array}$ \\
\hline Age of the Offender & & Property Value(in dollars) & $\begin{array}{c}338,183 \\
(496,443)\end{array}$ \\
\hline Juvenile & $\begin{array}{c}12.28 \\
(13.35)\end{array}$ & & \\
\hline Observations & 26,338 & & 26,338 \\
\hline
\end{tabular}

Notes: Standard deviations are in parentheses. Observations are weighted by the mean number of all crimes within the jurisdiction. 
Table 2: Summary Statistics on Weather Conditions

\begin{tabular}{l|c|cccccc}
\hline & Mean & $\begin{array}{c}\text { Std. } \\
\text { Dev. }\end{array}$ & $10^{\text {th }}$ & $25^{\text {th }}$ & $50^{\text {th }}$ & $75^{\text {th }}$ & $90^{\text {th }}$ \\
\hline $\begin{array}{l}\text { Average Temperature (n=26,338) } \\
\text { Inches of Precipitation (n=26,338) }\end{array}$ & 57.72 & 16.88 & 34.00 & 45.85 & 59.19 & 71.82 & 78.40 \\
$\begin{array}{l}\text { Inches of Precipitation (n=22,967) } \\
\text { (Conditional on some precipitation) }\end{array}$ & 0.13 & 0.15 & 0.00 & 0.01 & 0.06 & 0.16 & 0.28 \\
$\begin{array}{l}\text { Inches of Snowfall (n=25,418) } \\
\begin{array}{l}\text { Inches of Snowfall (n=4,259) } \\
\text { (Conditional on some snowfall) }\end{array}\end{array}$ & 0.06 & 0.25 & 0.00 & 0.00 & 0.00 & 0.00 & 0.10 \\
& 0.40 & 0.52 & 0.02 & 0.07 & 0.21 & 0.51 & 1.00 \\
$\begin{array}{l}\text { Inches of Snowcover (n=25,130) } \\
\begin{array}{l}\text { Inches of Snowcover (n=4,078) } \\
\text { (Conditional on some snowcover) }\end{array}\end{array}$ & 0.05 & 0.21 & 0.00 & 0.00 & 0.00 & 0.00 & 0.04 \\
\hline
\end{tabular}

Notes: The unit of observation for all statistics is the one week average for a particular jurisdiction. Average temperature is the simple average of the recorded minimum and maximum daily temperature, then averaged across the week. Standard deviations are in parentheses. Observations are weighted by the mean number of all crimes within the jurisdiction. 
Table 3: The Relationship between Weather and Crime

\begin{tabular}{|c|c|c|c|c|c|c|c|c|}
\hline & \multicolumn{4}{|c|}{ Violent Crime in Period t } & \multicolumn{4}{|c|}{ Property Crime in Period t } \\
\hline & (1) & (2) & $(3)$ & (4) & (5) & (6) & $(7)$ & (8) \\
\hline Temperature/100 & $\begin{array}{l}0.492 * * \\
(0.029)\end{array}$ & $\begin{array}{c}0.475^{* *} \\
(0.030)\end{array}$ & $\begin{array}{c}0.356^{* *} \\
(0.080)\end{array}$ & & $\begin{array}{l}0.291 * * \\
(0.025)\end{array}$ & $\begin{array}{l}0.263 * * \\
(0.026)\end{array}$ & $\begin{array}{l}0.810^{* * *} \\
(0.070)\end{array}$ & \\
\hline Precipitation & $\begin{array}{c}-0.098 * * \\
(0.010)\end{array}$ & $\begin{array}{c}-0.096 * * \\
(0.010)\end{array}$ & $\begin{array}{c}-0.122 * * \\
(0.015)\end{array}$ & & $\begin{array}{l}-0.008 \\
(0.008)\end{array}$ & $\begin{array}{l}-0.002 \\
(0.009)\end{array}$ & $\begin{array}{l}-0.004 \\
(0.013)\end{array}$ & \\
\hline Snow fall & & $\begin{array}{c}-0.026 * * \\
(0.010)\end{array}$ & & & & $\begin{array}{c}-0.026 * * \\
(0.006)\end{array}$ & & \\
\hline Snow cover & & $\begin{array}{c}0.035^{* *} \\
(0.015)\end{array}$ & & & & $\begin{array}{c}-0.030 * * \\
(0.010)\end{array}$ & & \\
\hline Temperature Squared & & & $\begin{array}{l}0.001 * \\
(0.001)\end{array}$ & & & & $\begin{array}{c}-0.005 * * \\
(0.001)\end{array}$ & \\
\hline Precipitation Squared & & & $\begin{array}{c}0.035 * * \\
(0.145)\end{array}$ & & & & $\begin{array}{l}-0.016 \\
(0.013)\end{array}$ & \\
\hline $\begin{array}{l}\text { Number of days in the week with } \\
\text { average temperature: }\end{array}$ & & & & & & & & \\
\hline Between 10-20 degrees & & & & $\begin{array}{c}0.001 \\
(0.005)\end{array}$ & & & & $\begin{array}{r}0.009 * * \\
(0.004)\end{array}$ \\
\hline Between 20-30 degrees & & & & $\begin{array}{c}0.011 * * \\
(0.004)\end{array}$ & & & & $\begin{array}{c}0.019 * * \\
(0.003)\end{array}$ \\
\hline Between 30-40 degrees & & & & $\begin{array}{c}0.017 * * \\
(0.004)\end{array}$ & & & & $\begin{array}{c}0.027 * * \\
(0.003)\end{array}$ \\
\hline Between 40-50 degrees & & & & $\begin{array}{l}0.020 * * \\
(0.004)\end{array}$ & & & & $\begin{array}{c}0.032 * * \\
(0.003)\end{array}$ \\
\hline Between 50-60 degrees & & & & $\begin{array}{c}0.029 * * \\
(0.004)\end{array}$ & & & & $\begin{array}{c}0.036 * * \\
(0.004)\end{array}$ \\
\hline Between 60-70 degrees & & & & $\begin{array}{c}0.037 * * \\
(0.004)\end{array}$ & & & & $\begin{array}{c}0.038 * * \\
(0.004)\end{array}$ \\
\hline Between 70-80 degrees & & & & $\begin{array}{l}0.046^{* *} \\
(0.004)\end{array}$ & & & & $\begin{array}{c}0.039 * * \\
(0.004)\end{array}$ \\
\hline Between 80-90 degrees & & & & $\begin{array}{l}0.048 * * \\
(0.004)\end{array}$ & & & & $\begin{array}{l}0.039 * * \\
(0.004)\end{array}$ \\
\hline
\end{tabular}


Above 90 degrees

Number of days in the week with total precipitation:

Between 0.01-0.25 inches

Between 0.25-0.50 inches

Between 0.50-0.75 inches

Between 0.75-1.00 inches

More than 1 inch

F-Statistic for Joint Significance

R-Squared
Observations
$0.053^{* *}$

(0.007)

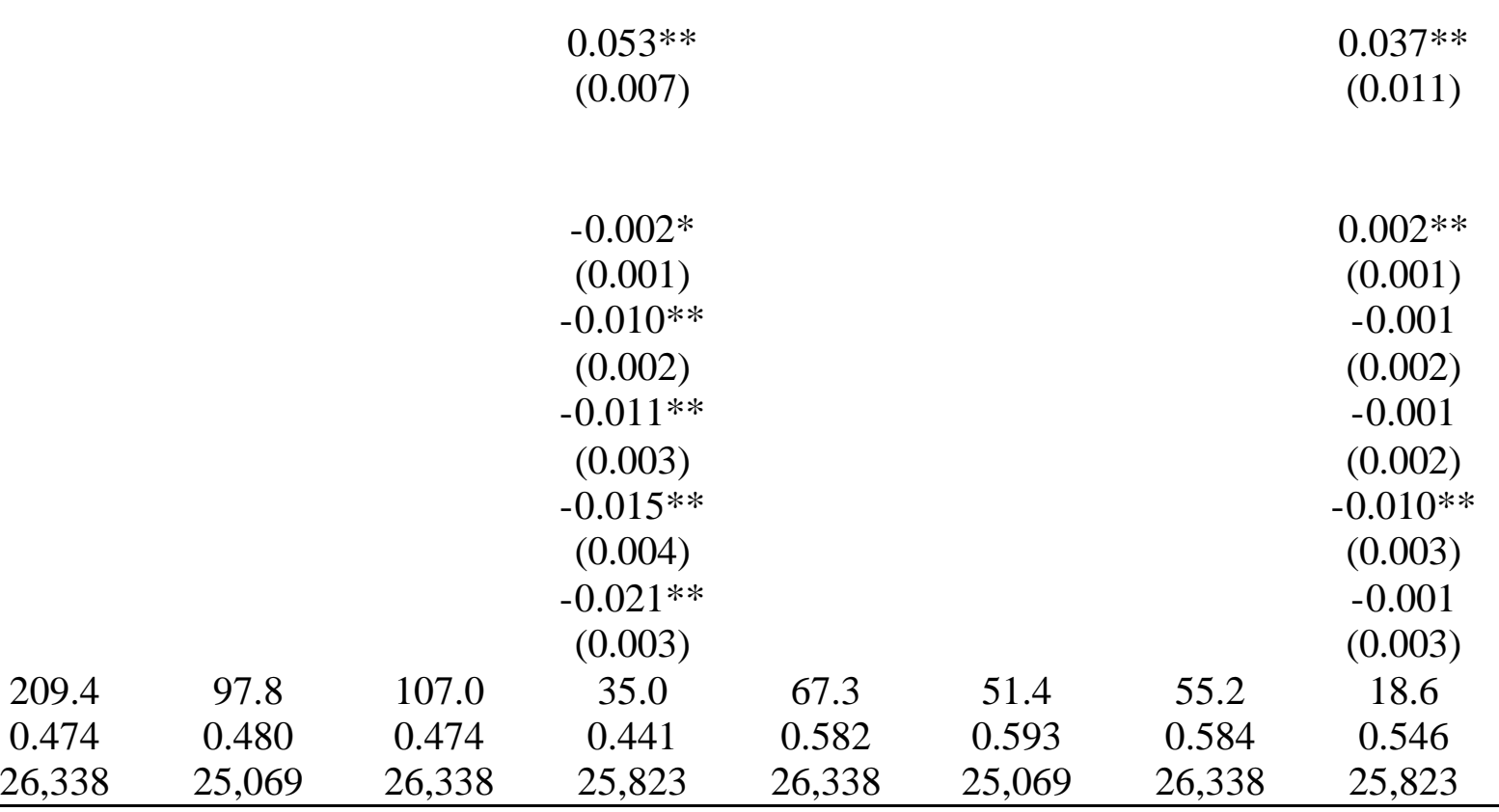

Notes: All crime rates are computed by dividing the actual number of crimes during a week by the average number of weekly crimes within the jurisdiction. All models include jurisdiction-year fixed effects, jurisdiction-specific $4^{\text {h }}$ order polynomials in day-of-year, and fixed effects for month. Standard errors in parenthesis. Standard errors are clustered at the state*year*month level to take into account the correlation across jurisdictions within a state and within a jurisdiction over time. All weather variables are weekly averages. Precipitation is measured in inches. Observations are weighted by the mean number of all crimes within the jurisdiction. $*=$ significant at the $10 \%$ level; $* *=$ significant at the $5 \%$ level. 
Table 4: The Relationship between Weather and Crime, by Type of Crime

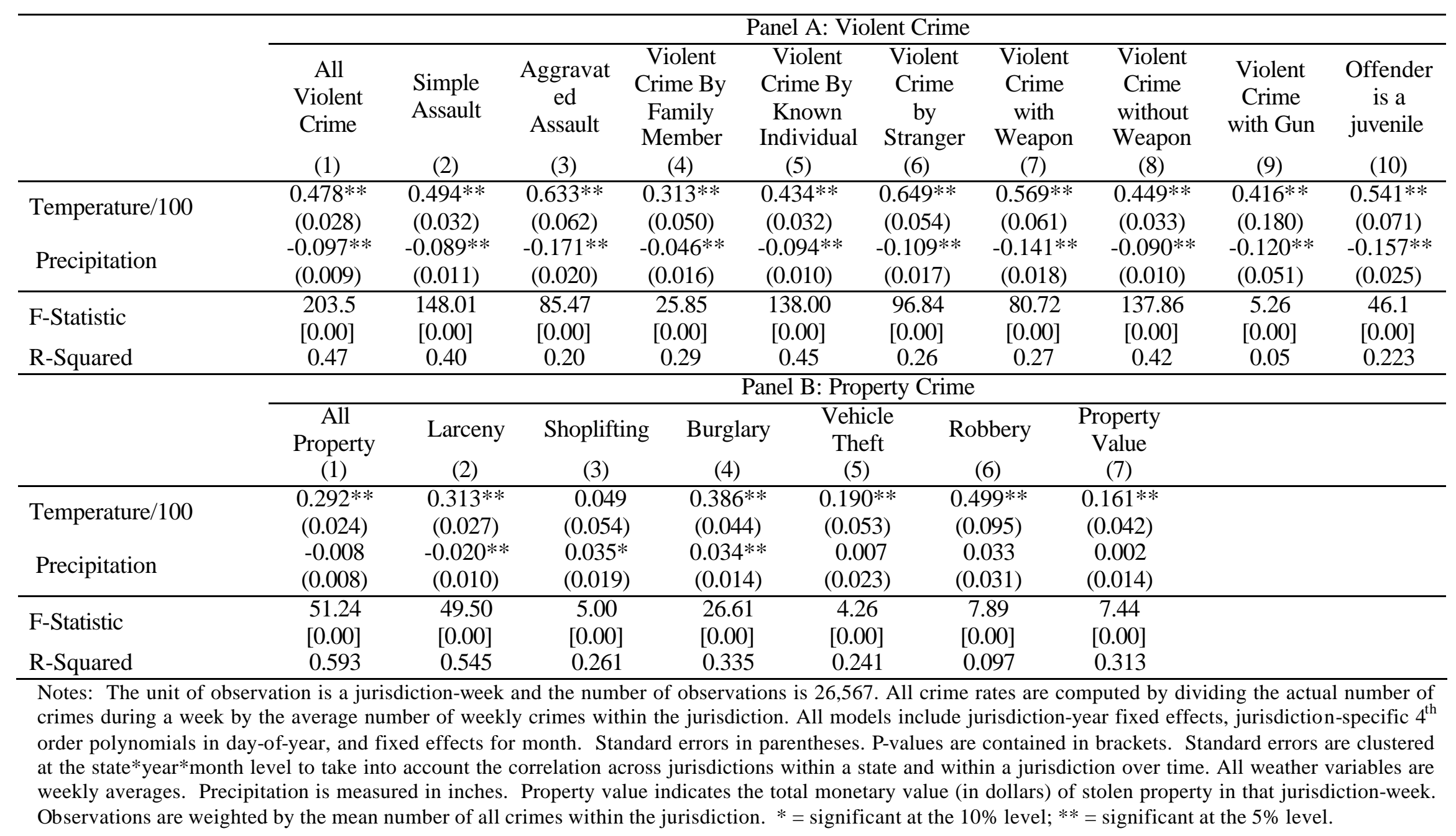


Table 5: OLS and IV Estimates of the Relationship between Current and Lagged Violent Crime

\begin{tabular}{|c|c|c|c|c|c|c|c|c|}
\hline & \multicolumn{8}{|c|}{ Dependent Variable: Violent Crime in Period t } \\
\hline & OLS & IV & OLS & IV & OLS & IV & OLS & IV \\
\hline & $(1)$ & $(2)$ & (3) & (4) & $(5)$ & $(6)$ & $(7)$ & $(8)$ \\
\hline \multirow{2}{*}{ Crime t-1 } & $0.083^{* *}$ & $-0.260 * *$ & $0.077 * *$ & $-0.209 * *$ & $0.072 * *$ & $-0.215^{* *}$ & $0.068 * *$ & $-0.221 * *$ \\
\hline & $(0.010)$ & $(0.054)$ & $(0.009)$ & $(0.050)$ & $(0.009)$ & $(0.049)$ & $(0.008)$ & $(0.050)$ \\
\hline \multirow{2}{*}{ Crime $\mathrm{t}-2$} & -0 & 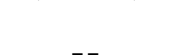 & $0.052 * *$ & $-0.172 * *$ & $0.047 * *$ & $-0.159 * *$ & $0.043 * *$ & $-0.159 * *$ \\
\hline & -- & -- & $(0.008)$ & $(0.052)$ & $(0.008)$ & $(0.045)$ & $(0.008)$ & $(0.047)$ \\
\hline \multirow{2}{*}{ Crime $\mathrm{t}-3$} & -- & -- & -- & -- & $0.032 * *$ & -0.070 & $0.026 * *$ & -0.049 \\
\hline & & & & & $(0.008)$ & $(0.052)$ & $(0.008)$ & $(0.047)$ \\
\hline Crime $\mathrm{t}-4$ & -- & -- & -- & -- & -- & -- & $\begin{array}{c}0.049 * * \\
(0.008)\end{array}$ & $\begin{array}{c}-0.105 * * \\
(0.054)\end{array}$ \\
\hline Sum of Coefficients & $\begin{array}{c}0.083 * * \\
(0.010)\end{array}$ & $\begin{array}{l}-0.260 * * \\
(0.053)\end{array}$ & $\begin{array}{l}0.129 * * \\
(0.014)\end{array}$ & $\begin{array}{c}-0.381 * * \\
(0.068)\end{array}$ & $\begin{array}{c}0.151 * * \\
(0.018)\end{array}$ & $\begin{array}{c}-0.444 * * \\
(0.086)\end{array}$ & $\begin{array}{c}0.186 * * \\
(0.010)\end{array}$ & $\begin{array}{l}-0.536 * * \\
(0.128)\end{array}$ \\
\hline F-Statistic -Sum of & & & 70.27 & 52.77 & 70.7 & 28.14 & 91.94 & 26.09 \\
\hline Coefficients [p-value] & & & {$[0.00]$} & {$[0.00]$} & {$[0.00]$} & {$[0.00]$} & {$[0.00]$} & {$[0.00]$} \\
\hline F-Statistic-First Stage & & 213.58 & -- & $112.5-113.0$ & & $81.1-78.3$ & -- & $59.9-66.0$ \\
\hline [p-value] & -- & {$[0.00]$} & -- & {$[0.00-0.00]$} & -- & {$[0.00-0.00]$} & -- & {$[0.00-0.00]$} \\
\hline Observations & 26,338 & 26,338 & 25,929 & 25,929 & 25,893 & 25,893 & 25,853 & 25,853 \\
\hline Period t Weather & Yes & Yes & Yes & Yes & Yes & Yes & Yes & Yes \\
\hline $\begin{array}{l}\text { Jurisdiction*Year } \\
\text { Effects }\end{array}$ & Yes & Yes & Yes & Yes & Yes & Yes & Yes & Yes \\
\hline Month Effects & Yes & Yes & Yes & Yes & Yes & Yes & Yes & Yes \\
\hline Jurisdiction Specific $4^{\text {th }}$ & & & & & & & & \\
\hline $\begin{array}{l}\text { Order Polynomial in } \\
\text { Day of Year }\end{array}$ & Yes & Yes & Yes & Yes & Yes & Yes & Yes & Yes \\
\hline
\end{tabular}

Notes: The unit of observation is a jurisdiction-week. The number of observations vary depending on the number of lags included. All crime rates are computed by dividing the actual number of crimes during a week by the average number of weekly crimes within the jurisdiction. Standard errors in parenthesis. Standard errors are clustered at the state*year*month level to take into account the correlation across jurisdictions within a state and within a jurisdiction over time. Pvalues for the F-statistics are shown in brackets. For models with multiple instruments, minimum and maximum F-statistic and p-value are shown. Observations are weighted by the mean number of all crimes within the jurisdiction. $*=$ significant at the $10 \%$ level; $* *=$ significant at the $5 \%$ level. 
Table 6: OLS and IV Estimates of the Relationship between Current and Lagged Property Crime

\begin{tabular}{|c|c|c|c|c|c|c|c|c|}
\hline & \multicolumn{8}{|c|}{ Dependent Variable: Property Crime in Period t } \\
\hline & OLS & IV & OLS & IV & OLS & IV & OLS & IV \\
\hline & $(1)$ & $(2)$ & $(3)$ & (4) & $(5)$ & $(6)$ & $(7)$ & $(8)$ \\
\hline \multirow{2}{*}{ Crime t- 1} & $0.279 * *$ & $-0.201 * *$ & $0.241 * *$ & $-0.171^{*} *$ & $0.233 * *$ & $-0.176^{* *}$ & $0.229 * *$ & $-0.172 * *$ \\
\hline & $(0.012)$ & $(0.083)$ & $(0.010)$ & $(0.080)$ & $(0.010)$ & $(0.084)$ & $(0.010)$ & $(0.084)$ \\
\hline \multirow{2}{*}{ Crime $\mathrm{t}-2$} & 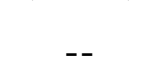 & 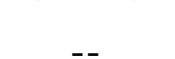 & $0.127 * *$ & $-0.136^{*}$ & $0.112 * *$ & $-0.138 *$ & $0.104 * *$ & $-0.149 *$ \\
\hline & -- & -- & $(0.008)$ & $(0.090)$ & $(0.008)$ & $(0.083)$ & $(0.007)$ & $(0.084)$ \\
\hline \multirow{2}{*}{ Crime $\mathrm{t}-3$} & -- & -- & -- & 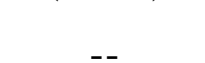 & $0.054 * *$ & -0.011 & $0.040 * *$ & -0.016 \\
\hline & -- & -- & -- & -- & $(0.008)$ & $(0.083)$ & $(0.007)$ & $(0.084)$ \\
\hline Crime $\mathrm{t}-4$ & -- & -- & -- & -- & -- & -- & $\begin{array}{c}0.056^{* *} \\
(0.008)\end{array}$ & $\begin{array}{l}-0.010 \\
(0.096)\end{array}$ \\
\hline \multirow[t]{2}{*}{ Sum of Coefficients } & $0.279 * *$ & $-0.201 * *$ & $0.368 * *$ & $-0.307 * *$ & $0.399 * *$ & $-0.325 * *$ & $0.429 * *$ & $-0.326^{*}$ \\
\hline & $(0.012)$ & $(0.083)$ & $(0.014)$ & $(0.116)$ & $(0.015)$ & $(0.137)$ & $(0.016)$ & $(0.204)$ \\
\hline F-Statistic-Sum of & & & 651.91 & 9.88 & 656.05 & 6.93 & 653.77 & 4.58 \\
\hline Coefficients [p-value] & & & {$[0.00]$} & {$[0.00]$} & {$[0.00]$} & {$[0.01]$} & {$[0.00]$} & {$[0.03]$} \\
\hline F-Statistic - First Stage & & 64.06 & 5 & $33.0-34.5$ & 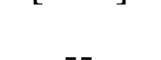 & $21.9-23.6$ & 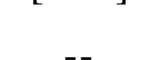 & $15.7-18.4$ \\
\hline [p-value] & -- & {$[0.00]$} & & {$[0.00-0.00]$} & & {$[0.00-0.00]$} & & {$[0.00-0.00]$} \\
\hline Observations & 26,338 & 26,338 & 25,929 & 25,929 & 25,893 & 25,893 & 25,853 & 25,853 \\
\hline Period t Weather & Yes & Yes & Yes & Yes & Yes & Yes & Yes & Yes \\
\hline $\begin{array}{l}\text { Jurisdiction*Year } \\
\text { Effects }\end{array}$ & Yes & Yes & Yes & Yes & Yes & Yes & Yes & Yes \\
\hline Month Effects & Yes & Yes & Yes & Yes & Yes & Yes & Yes & Yes \\
\hline Jurisdiction Specific $4^{\text {th }}$ & & & & & & & & \\
\hline $\begin{array}{l}\text { Order Polynomial in } \\
\text { Day of Year }\end{array}$ & Yes & Yes & Yes & Yes & Yes & Yes & Yes & Yes \\
\hline
\end{tabular}

Notes: The unit of observation is a jurisdiction-week. The number of observations vary depending on the number of lags included. All crime rates are computed by dividing the actual number of crimes during a week by the average number of weekly crimes within the jurisdiction. Standard errors in parenthesis. Standard errors are clustered at the state*year*month level to take into account the correlation across jurisdictions within a state and within a jurisdiction over time. Pvalues for the F-statistics are shown in brackets. For models with multiple instruments, minimum and maximum F-statistic and p-value are shown. Observations are weighted by the mean number of all crimes within the jurisdiction. $*=$ significant at the $10 \%$ level; $* *=$ significant at the $5 \%$ level. 
Table 7: OLS and IV Estimates of the Impact of All Lagged Violent Crime on Specific Types of Violent Crime

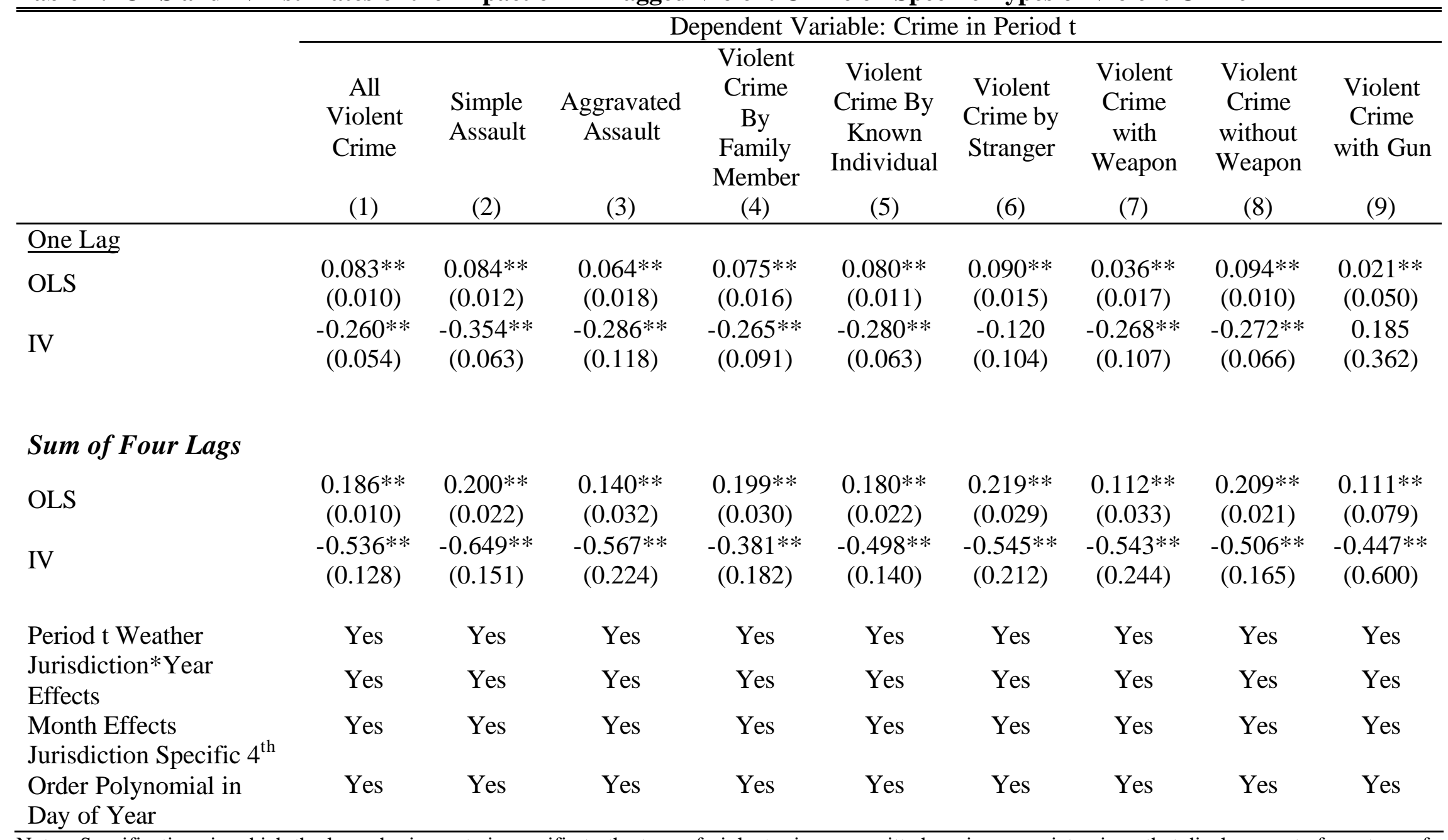

Notes: Specifications in which the lagged crime rate is specific to the type of violent crime committed are inappropriate given that displacement of one type of violent crime might be manifested subsequently by a violent crime of a different type. Thus for all specifications, the lagged variable is the rate of all violent crimes. The dependent variable is number of crimes divided by the average number of those types of crimes in the jurisdiction. For the one-lag models, the parentheses contain standard errors that errors are clustered at the state*year*month level to take into account the correlation across jurisdictions within a state and within a jurisdiction over time. For the four-lag models, the parentheses contain the standard error of the sum of the coefficients on all four lags. Observations are weighted by the mean number of all crimes within the jurisdiction. $*=$ significant at the $10 \%$ level; $* *=$ significant at the $5 \%$ level. 
Table 8: OLS and IV Estimates of the Impact of Lagged Crime on Specific Types of Property Crime

\begin{tabular}{|c|c|c|c|c|c|c|c|}
\hline & \multicolumn{6}{|c|}{ Dependent Variable: Crime in Period t } & \multirow{2}{*}{$\begin{array}{c}\text { Dependent Variable: } \\
\text { The total value of all } \\
\text { stolen property in period } \mathrm{t} \\
(7)\end{array}$} \\
\hline & $\begin{array}{c}\text { All } \\
\text { Property } \\
\text { (1) }\end{array}$ & $\begin{array}{c}\text { Larceny } \\
\text { (2) }\end{array}$ & $\begin{array}{c}\text { Shoplifting } \\
\text { (3) }\end{array}$ & $\begin{array}{c}\text { Burglary } \\
\text { (4) }\end{array}$ & $\begin{array}{l}\text { Vehicle } \\
\text { Theft } \\
\text { (5) }\end{array}$ & $\begin{array}{c}\text { Robbery } \\
\text { (6) }\end{array}$ & \\
\hline \multicolumn{8}{|l|}{ One Lag } \\
\hline OLS & $\begin{array}{c}0.279 * * \\
(0.012)\end{array}$ & $\begin{array}{c}0.284 * * \\
(0.012)\end{array}$ & $\begin{array}{c}0.176^{* * *} \\
(0.022)\end{array}$ & $\begin{array}{c}0.316 * * \\
(0.028)\end{array}$ & $\begin{array}{c}0.257 * * \\
(0.022)\end{array}$ & $\begin{array}{l}0.290 * * \\
(0.035)\end{array}$ & $\begin{array}{c}0.170 * * \\
(0.030)\end{array}$ \\
\hline IV & $\begin{array}{c}-0.201 * * \\
(0.083)\end{array}$ & $\begin{array}{l}-0.064 \\
(0.093)\end{array}$ & $\begin{array}{c}0.179 \\
(0.192)\end{array}$ & $\begin{array}{l}-0.209 \\
(0.160)\end{array}$ & $\begin{array}{c}-0.599 * * \\
(0.213)\end{array}$ & $\begin{array}{l}-0.009 \\
(0.367)\end{array}$ & $\begin{array}{c}-0.582^{* *} \\
(0.265)\end{array}$ \\
\hline \multicolumn{8}{|l|}{$\begin{array}{l}\text { Sum of Four } \\
\text { Lags }\end{array}$} \\
\hline OLS & $\begin{array}{c}0.429 * * \\
(0.016)\end{array}$ & $\begin{array}{c}0.438 * * \\
(0.018)\end{array}$ & $\begin{array}{c}0.336 * * \\
(0.035)\end{array}$ & $\begin{array}{c}0.519 * * \\
(0.042)\end{array}$ & $\begin{array}{c}0.416 * * \\
(0.035)\end{array}$ & $\begin{array}{l}0.372 * * \\
(0.052)\end{array}$ & $\begin{array}{c}0.343 * * \\
(0.06)\end{array}$ \\
\hline IV & $\begin{array}{l}-0.326^{*} \\
(0.204)\end{array}$ & $\begin{array}{l}-0.168 \\
(0.201)\end{array}$ & $\begin{array}{l}-0.207 \\
(0.352)\end{array}$ & $\begin{array}{l}-0.064 \\
(0.313)\end{array}$ & $\begin{array}{c}-1.091 * * \\
(0.481)\end{array}$ & $\begin{array}{l}-0.007 \\
(0.642)\end{array}$ & $\begin{array}{c}-3.99 \\
(3.311)\end{array}$ \\
\hline Period t Weather & Yes & Yes & Yes & Yes & Yes & Yes & Yes \\
\hline $\begin{array}{l}\text { Jurisdiction*Year } \\
\text { Effects }\end{array}$ & Yes & Yes & Yes & Yes & Yes & Yes & Yes \\
\hline $\begin{array}{l}\text { Month Effects } \\
\text { Jurisdiction }\end{array}$ & Yes & Yes & Yes & Yes & Yes & Yes & Yes \\
\hline $\begin{array}{l}\text { Specific } 4^{\text {th }} \text { Order } \\
\text { Polynomial in Day } \\
\text { of Year }\end{array}$ & Yes & Yes & Yes & Yes & Yes & Yes & Yes \\
\hline
\end{tabular}


Table 9: OLS and IV Estimates of the Relationship between Current and Lagged Traffic

\begin{tabular}{|c|c|c|c|c|c|c|c|c|}
\hline & \multicolumn{8}{|c|}{ Dependent Variable: Traffic Volume in Period t } \\
\hline & OLS & IV & OLS & IV & OLS & IV & OLS & IV \\
\hline & $(1)$ & (2) & $(3)$ & (4) & $(5)$ & (6) & $(7)$ & (8) \\
\hline \multirow{2}{*}{ Traffic t-1 } & $0.633^{*} *$ & 0.040 & $0.618^{* *}$ & 0.163 & $0.811 * *$ & -0.094 & $0.753 * *$ & 0.092 \\
\hline & $(0.024)$ & $(0.219)$ & $(0.030)$ & $(0.214)$ & $(0.009)$ & $(0.172)$ & $(0.016)$ & $(0.207)$ \\
\hline \multirow{2}{*}{ Traffic $\mathrm{t}-2$} & -- & -- & $-0.091 * *$ & -0.045 & -- & -- & $-0.029 *$ & -0.068 \\
\hline & & & $(0.029)$ & $(0.207)$ & -- & - & $(0.016)$ & $(0.220)$ \\
\hline \multirow{2}{*}{ Traffic $t-3$} & -- & -- & 0.025 & -0.001 & -- & & $0.041 * *$ & -0.204 \\
\hline & - & -- & $(0.031)$ & $(0.163)$ & -- & -- & $(0.017)$ & $(0.199)$ \\
\hline \multirow{2}{*}{ Traffic $\mathrm{t}-4$} & - & & 0.031 & -0.120 & -- & -- & $0.070 * *$ & 0.254 \\
\hline & -- & -- & $(0.026)$ & $(0.220)$ & -- & -- & $(0.014)$ & $(0.322)$ \\
\hline \multirow{4}{*}{$\begin{array}{l}\text { Sum of Coefficients } \\
\text { F-Statistic of Sum of } \\
\text { Coefficients [p-value] } \\
\text { F-Statistic of From First } \\
\text { Stage Regression [p- } \\
\text { value] }\end{array}$} & 0.633 & 0.007 & 0.583 & -0.003 & 0.811 & 0.192 & 0.853 & 0.074 \\
\hline & & & 259.32 & 0.16 & 7863.44 & 3.78 & 5634.99 & 0.30 \\
\hline & -- & & {$[0.00]$} & {$[0.90]$} & {$[0.00]$} & {$[0.05]$} & {$[0.00]$} & {$[0.68]$} \\
\hline & -- & $\begin{array}{c}9.35 \\
{[0.00]}\end{array}$ & -- & -- & -- & $\begin{array}{c}18.65 \\
{[0.00]}\end{array}$ & -- & -- \\
\hline Observations & 4,959 & 4,959 & 4,272 & 4,272 & 42,893 & 42,893 & 37,076 & 37,076 \\
\hline
\end{tabular}




\begin{tabular}{|c|c|c|c|c|c|}
\hline & & \multicolumn{2}{|c|}{ Violent Crime } & \multicolumn{2}{|c|}{ Property Crime } \\
\hline & & $\begin{array}{l}\text { IV Estimates } \\
\text { One Lag } \\
\text { Specification } \\
\text { (1) }\end{array}$ & $\begin{array}{l}\text { IV Estimates } \\
\text { Sum of First } \\
\text { Four Lags } \\
\text { (2) }\end{array}$ & $\begin{array}{l}\text { IV Estimates } \\
\text { One Lag } \\
\text { Specification } \\
\text { (3) }\end{array}$ & $\begin{array}{l}\text { IV Estimates } \\
\text { Sum of First } \\
\text { Four Lags } \\
\text { (4) }\end{array}$ \\
\hline 1 & Baseline Estimates (from Tables 5 and 6) & $\begin{array}{c}-0.260 * * \\
(0.054)\end{array}$ & $\begin{array}{c}-0.536^{* *} \\
(0.128)\end{array}$ & $\begin{array}{c}-0.201 * * \\
(0.083)\end{array}$ & $\begin{array}{c}-0.326^{*} \\
(0.204)\end{array}$ \\
\hline 2 & Dependent Variable Is the Indoor Crime Rate & $\begin{array}{c}-0.315^{* *} \\
(0.064)\end{array}$ & $\begin{array}{c}-0.526 * * \\
(0.143)\end{array}$ & $\begin{array}{c}-0.184 * * \\
(0.087)\end{array}$ & $\begin{array}{l}-0.198 \\
(0.189)\end{array}$ \\
\hline 3 & Dependent Variable is the Outdoor Crime Rate & $\begin{array}{l}-0.068 \\
(0.111)\end{array}$ & $\begin{array}{c}-0.423 * * \\
(0.204)\end{array}$ & $\begin{array}{l}-0.158 \\
(0.169)\end{array}$ & $\begin{array}{l}-0.336 \\
(0.366)\end{array}$ \\
\hline 4 & $\begin{array}{l}\text { Right-Hand Side Variables are Future Weather Conditions } \\
\text { (Reverse Experiment) }\end{array}$ & $\begin{array}{c}0.062 \\
(0.049)\end{array}$ & $\begin{array}{c}0.040 \\
(0.095)\end{array}$ & $\begin{array}{c}0.045 \\
(0.077)\end{array}$ & $\begin{array}{l}-0.166 \\
(0.169)\end{array}$ \\
\hline 5 & The Unit of Analysis Is the Log Number of Crimes & $\begin{array}{c}-0.263 * * \\
(0.062)\end{array}$ & $\begin{array}{l}-0.507 * * \\
(0.138)\end{array}$ & $\begin{array}{l}-0.230 * * \\
(0.093)\end{array}$ & $\begin{array}{r}-0.364 \\
(0.237)\end{array}$ \\
\hline 6 & Instruments Include Only Lagged Temperature & $\begin{array}{c}-0.338 * * \\
(0.059)\end{array}$ & $\begin{array}{l}-0.570 * * \\
(0.166)\end{array}$ & $\begin{array}{c}-0.199 * * \\
(0.083)\end{array}$ & $\begin{array}{l}-0.429 * \\
(0.240)\end{array}$ \\
\hline 7 & Instruments Include Only Lagged Measures of Precipitation & $\begin{array}{l}-0.005 \\
(0.115)\end{array}$ & $\begin{array}{l}-0.553 * * \\
(0.218)\end{array}$ & $\begin{array}{l}-3.12 \\
(8.71)\end{array}$ & $\begin{array}{l}-3.12 \\
(4.27)\end{array}$ \\
\hline 8 & $\begin{array}{l}\text { Instruments Include Lagged Measures of Precipitation, } \\
\text { Temperature, Snow and Snow Cover }\end{array}$ & $\begin{array}{l}-0.272 * * \\
(0.056)\end{array}$ & $\begin{array}{l}-0.453 * * \\
(0.109)\end{array}$ & $\begin{array}{l}-0.213 * * \\
(0.081)\end{array}$ & $\begin{array}{l}-0.460 * * \\
(0.209)\end{array}$ \\
\hline 9 & $\begin{array}{l}\text { Instruments Include Only Lagged Measures of Temperature } \\
\text { Above State*Month Average }\end{array}$ & $\begin{array}{c}-0.279 * * \\
(0.068)\end{array}$ & $\begin{array}{l}-0.511 * * \\
(0.158)\end{array}$ & $\begin{array}{l}-0.260 * * \\
(0.134)\end{array}$ & $\begin{array}{l}-0.275 \\
(0.285)\end{array}$ \\
\hline 10 & $\begin{array}{l}\text { Instruments Include Only Lagged Measures of Temperature } \\
\text { Below State*Month Average }\end{array}$ & $\begin{array}{l}-0.161 * * \\
(0.060)\end{array}$ & $\begin{array}{l}-0.502 * * \\
(0.131)\end{array}$ & $\begin{array}{l}-0.123 \\
(0.080)\end{array}$ & $\begin{array}{r}-0.198 \\
(0.174)\end{array}$ \\
\hline
\end{tabular}

Notes: All crime rates are computed by dividing the actual number of crimes during a week by the average number of weekly crimes within the jurisdiction. For the one-lag models, the standard error is presented in parenthesis below the coefficient. For the four-lag models, the parenthesis contain the standard error on the sum of all four lags. All standard errors are clustered at the state*year*month level to take into account the correlation across jurisdictions within a state and within a jurisdiction over time. Observations are weighted by the mean number of all crimes within the jurisdiction. $*=$ significant at the $10 \%$ level; $* *=$ significant at the $5 \%$ level. 


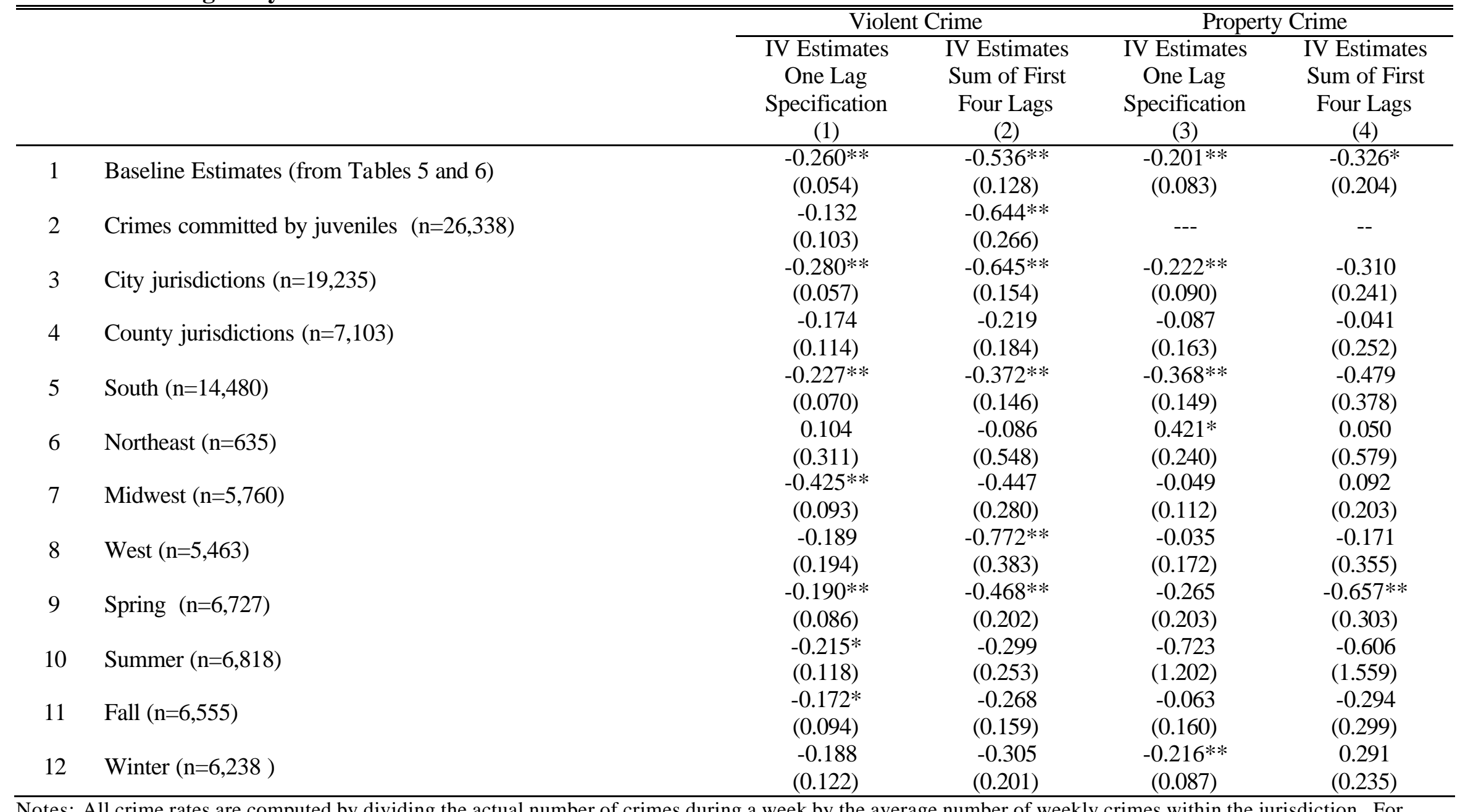

Notes: All crime rates are computed by dividing the actual number of crimes during a week by the average number of weekly crimes within the jurisdiction. For the one-lag models, the standard error is presented in parenthesis below the coefficient. For the four-lag models, the parenthesis contain the standard error on the sum of all four lags. All standard errors are clustered at the state*year*month level to take into account the correlation across jurisdictions within a state and within a jurisdiction over time. Observations are weighted by the mean number of all crimes within the jurisdiction. $*=$ significant at the $10 \%$ level; $* *=$ significant at the 5\% level. 
Table A1: Jurisdictions included in the analysis

\begin{tabular}{|c|c|c|c|}
\hline Jurisdiction & Years in Sample & Jurisdiction & Years in Sample \\
\hline Adams County, CO & $1997-2001$ & Knox County, TN & 1998-2001 \\
\hline Aiken County, SC & $1995-2001$ & Knoxville, TN & $2000-2001$ \\
\hline Akron, $\mathrm{OH}$ & $1998-2001$ & Lakewood, CO & $1997-2001$ \\
\hline Albemarle County, VA & $1997-2001$ & Layton, UT & $1995-2001$ \\
\hline Alexandria, VA & $2000-2001$ & Lexington County, SC & $1995-2001$ \\
\hline Anderson County, SC & $1995-2001$ & Loudoun County, VA & $1999-2001$ \\
\hline Arapahoe County, CO & $1997-2001$ & Lynchburg, VA & $2000-2001$ \\
\hline Aurora, CO & $1997-2001$ & Memphis, TN & $2000-2001$ \\
\hline Austin, TX & $1998-2001$ & Murfreesboro, TN & $1998-2001$ \\
\hline Battle Creek, MI & $1995-2001$ & Murray, UT & $1997-2001$ \\
\hline Beaufort County, SC & $1995-2001$ & Muskegon, MI & $2000-2001$ \\
\hline Berkeley County, SC & $1995-2001$ & Myrtle Beach, SC & $1995-2001$ \\
\hline Boise, ID & $1995-2001$ & Nampa, ID & $1995-2001$ \\
\hline Burlington, VT & 1999-2001 & Nashville, TN & $2000-2001$ \\
\hline Cedar Rapids, IA & $1999-2001$ & Newark, OH & $1998-2001$ \\
\hline Charleston County, SC & $1995-2001$ & Newport News, VA & $1998-2001$ \\
\hline Charleston, SC & $1995-2001$ & Norfolk, VA & $1999-2001$ \\
\hline Charleston, WV & 1999-2001 & North Charleston, SC & $1995-2001$ \\
\hline Charlottesville, VA & $1997-2001$ & Norwalk, CT & 1999-2001 \\
\hline Chattanooga, TN & $2000-2001$ & Oakland County, MI & $1997-2001$ \\
\hline Cherokee County, SC & $1995-2001$ & Olathe, KS & $2000-2001$ \\
\hline Chesterfield County, VA & 1999-2001 & Orangeburg County, SC & $1995-2001$ \\
\hline Cincinnati, $\mathrm{OH}$ & $1998-2001$ & Paducah, KY & $1998-2001$ \\
\hline Clarksville, TN & $1998-2001$ & Petersburg, VA & $1995-2001$ \\
\hline Cleveland, TN & $1999-2001$ & Pocatello, ID & $1995-2001$ \\
\hline Coeur D'Alene, ID & $1995-2001$ & Pontiac, MI & $1997-2001$ \\
\hline Colorado Springs, CO & $1997-2001$ & Portsmouth, VA & $2000-2001$ \\
\hline Columbia, SC & $1995-2001$ & Provo, UT & $1995-2001$ \\
\hline Columbia, TN & 1998-2001 & Redford, MI & $1997-2001$ \\
\hline Conroe, TX & $1998-2001$ & Richland County, SC & $1995-2001$ \\
\hline Council Bluffs, IA & $1995-2001$ & Richmond, VA & $2000-2001$ \\
\hline Danville, VA & $2000-2001$ & Riley County, KS & $2000-2001$ \\
\hline Davenport, IA & $1995-2001$ & Roanoke, VA & 1999-2001 \\
\hline Dayton, $\mathrm{OH}$ & 1998-2001 & Rock Hill, SC & $1995-2001$ \\
\hline Des Moines, IA & 1995-2001 & Roseville, MI & 1996-2001 \\
\hline Fairfax County, VA & $2000-2001$ & Saginaw, MI & $2000-2001$ \\
\hline Fargo, ND & $1995-2001$ & Salina, KS & $2000-2001$ \\
\hline Florence County, SC & $1995-2001$ & San Angelo, TX & $2000-2001$ \\
\hline Florence, $\mathrm{SC}$ & $1995-2001$ & Sandy, UT & $1995-2001$ \\
\hline Garden City, KS & 2000-2001 & Sioux City, IA & 1995-2001 \\
\hline Grand Forks, ND & $1995-2001$ & Southfield, MI & 1996-2001 \\
\hline Greenville County, SC & $1995-2001$ & Spartanburg County, SC & $1995-2001$ \\
\hline Greenville, SC & $1995-2001$ & Spartanburg, SC & $1995-2001$ \\
\hline Greenwood, SC & $1995-2001$ & Spotsylvania County, VA & $1999-2001$ \\
\hline Hamilton County, $\mathrm{OH}$ & $2000-2001$ & Springfield, MA & 1996-2001 \\
\hline Hampton, VA & $2000-2001$ & Stafford County, VA & $1997-2001$ \\
\hline Henrico County, VA & 1999-2001 & Suffolk, VA & $1997-2001$ \\
\hline Horry, SC & 1995-2001 & Sumter, SC & $1995-2001$ \\
\hline
\end{tabular}




\begin{tabular}{|l|l|l|c|}
\hline Huntington, WV & $2000-2001$ & Twin Falls, ID & $1995-2001$ \\
\hline Hutchinson, KS & $2000-2001$ & Virginia Beach, VA & $1999-2001$ \\
\hline Idaho Falls, ID & $1995-2001$ & Warren, MI & $1999-2001$ \\
\hline Iowa City, IA & $1995-2001$ & Waterford, MI & $2000-2001$ \\
\hline Jackson, TN & $1999-2001$ & Waterloo, IA & $1995-2001$ \\
\hline Jefferson County, CO & $1997-2001$ & West Jordan, UT & $1995-2001$ \\
\hline Johnson City, TN & $1998-2001$ & West Valley, UT & $1996-2001$ \\
\hline Junction City, KS & $2000-2001$ & Worcester, MA & $1995-2001$ \\
\hline Kalamazoo, MI & $2000-2001$ & Wyoming, MI & $1999-2001$ \\
\hline Kingsport, TN & $1998-2001$ & York County, SC & $1995-2001$ \\
\hline
\end{tabular}




\section{Figure 1: The Persistence of Crime}

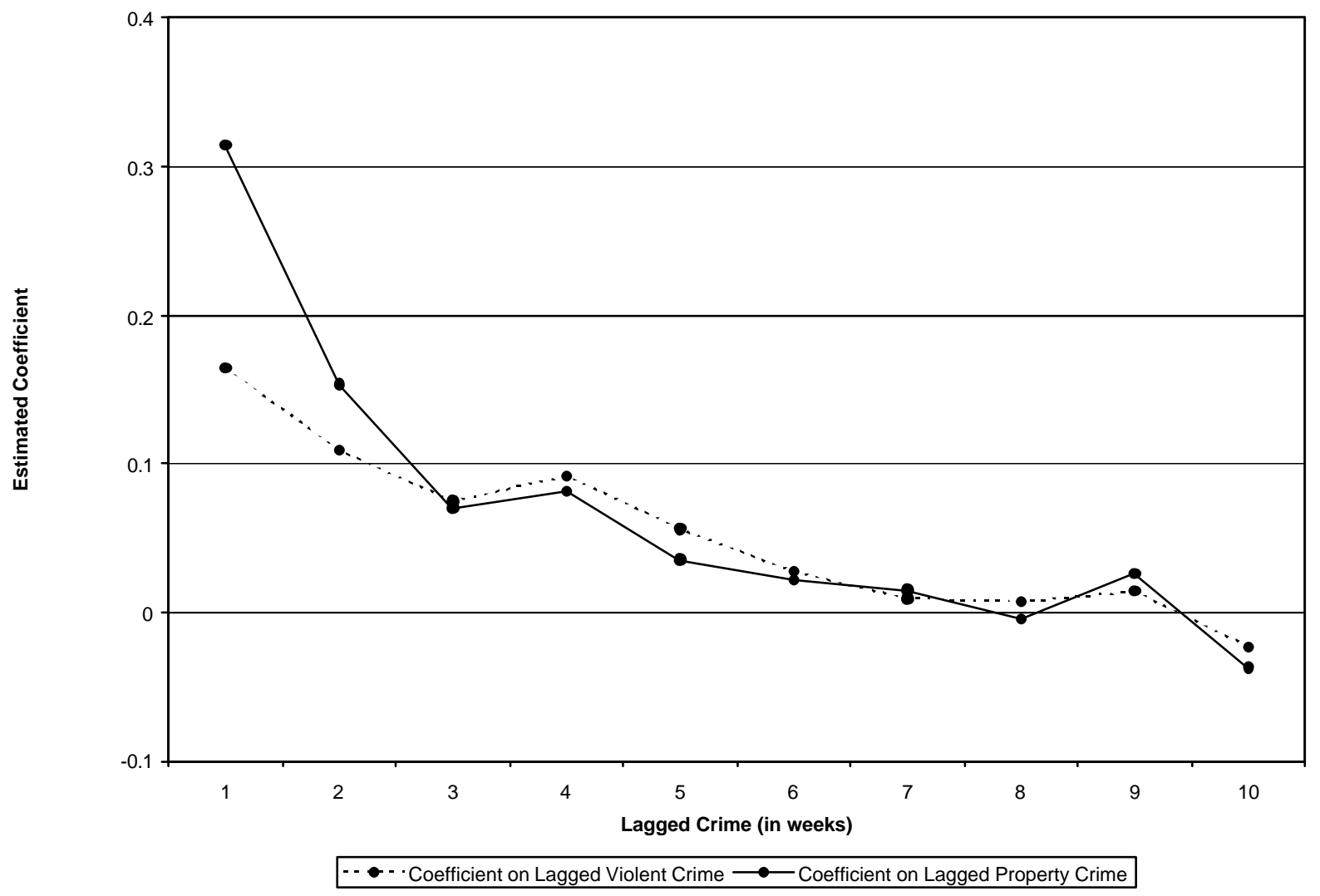

Notes: This figure shows the coefficient estimates from two separate regressions of current crime (violent or property) on ten lags of crime (violent or property). The unit of observation is a jurisdiction-week. All crime rates are computed by dividing the actual number of crimes during a week by the average number of weekly crimes within the jurisdiction. Other covariates include jurisdiction fixed effects. Standard errors in parenthesis are clustered at the state*year*month level. Observations are weighted by the mean number of all crimes within the jurisdiction. 


\section{Figure 2: The Estimated Relationship between Current and Lagged Violent Crime}

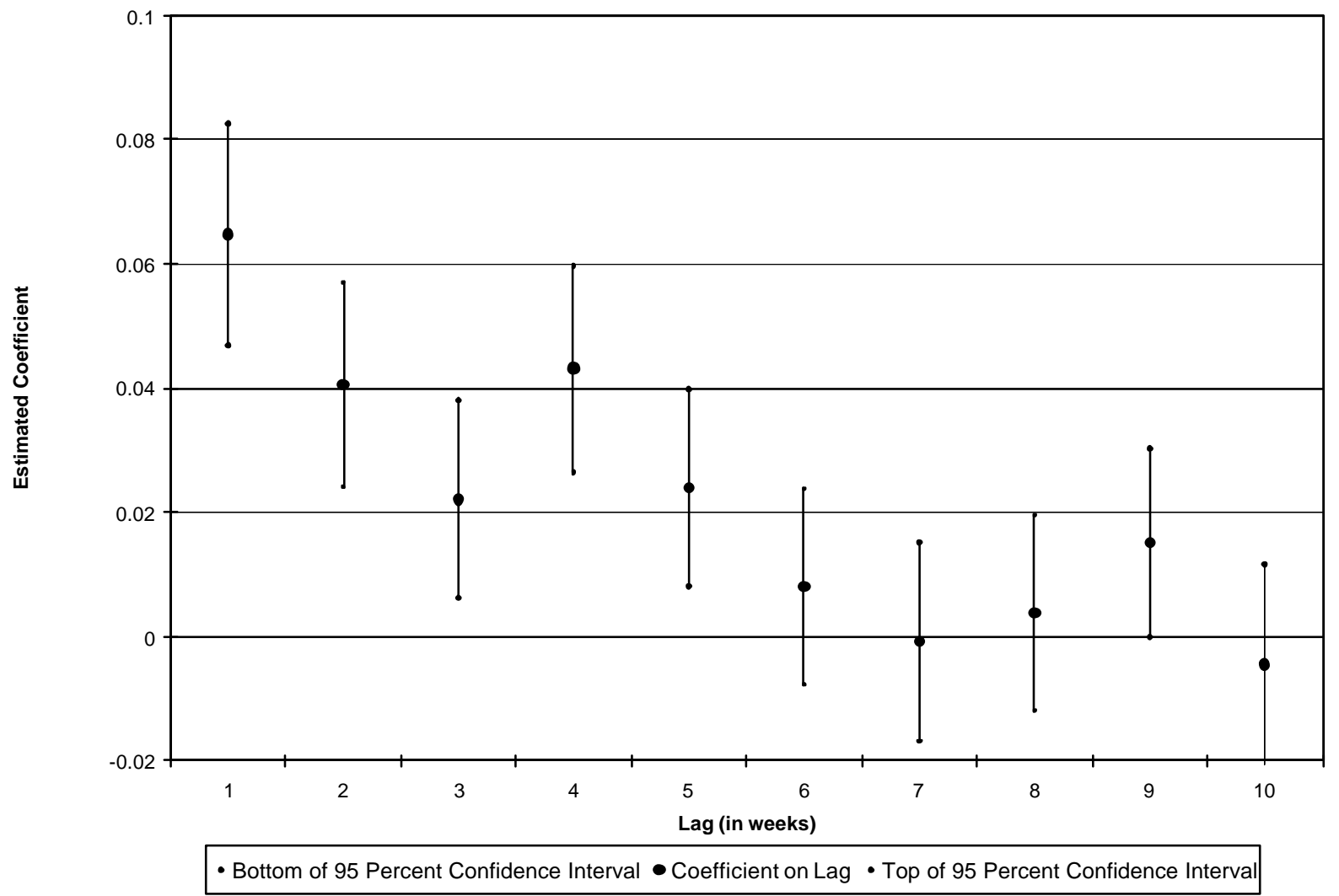

Notes: This figure shows the coefficient estimates from a regression of current violent crime on 10 lags of violent crime. The unit of observation is a jurisdiction-week. All crime rates are computed by dividing the actual number of crimes during a week by the average number of weekly crimes within the jurisdiction. Other covariates include average temperature and total precipitation in the current period, jurisdiction-year fixed effects, jurisdiction-specific $4^{\text {th }}$ order polynomials in day-of-year, and fixed effects for month. Standard errors in parenthesis are clustered at the state*year*month level. Observations are weighted by the mean number of all crimes within the jurisdiction. 


\section{Figure 3: The Estimated Relationship between Current and Lagged Property Crime}

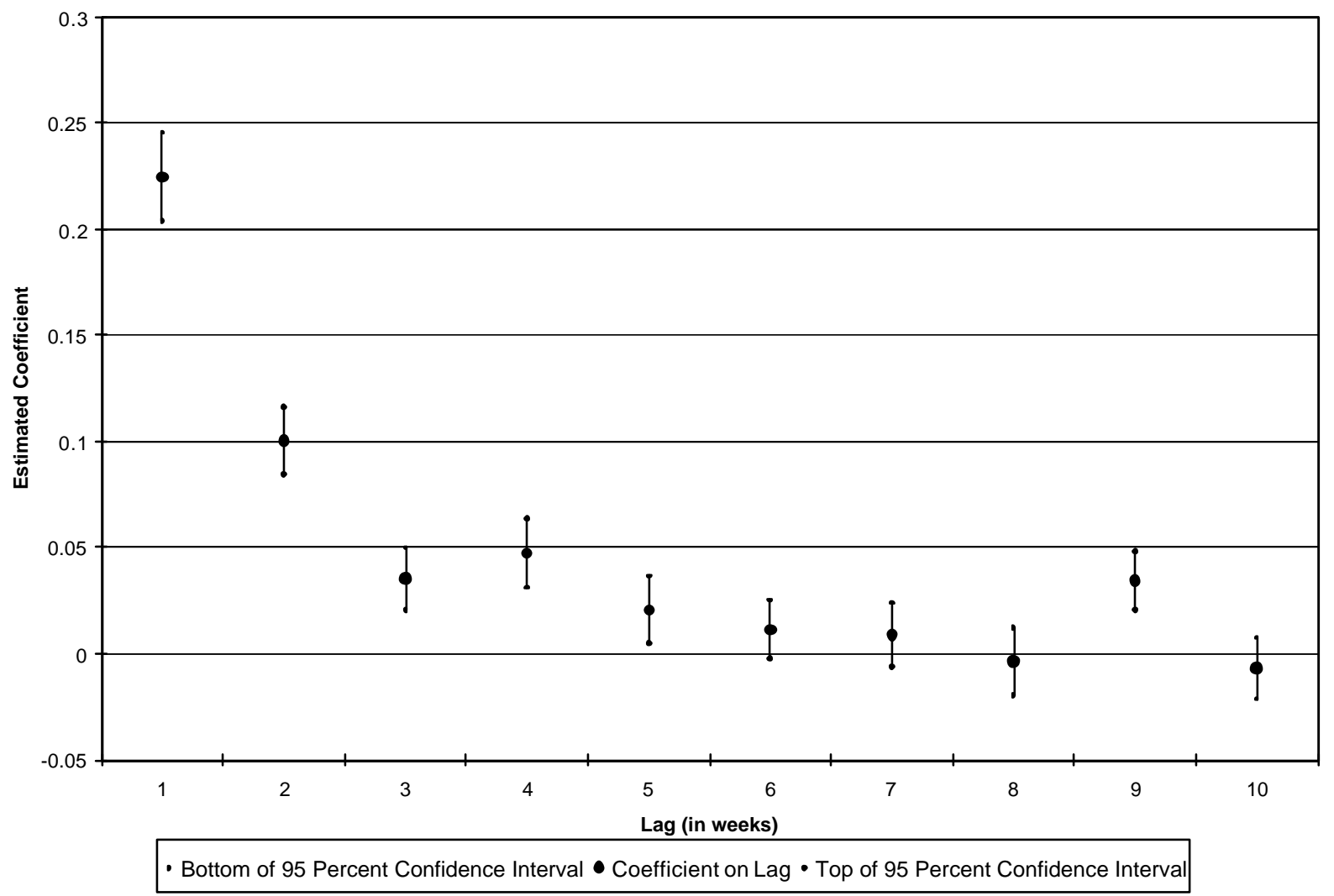

Notes: This figure shows the coefficient estimates from a regression of current property crime on 10 lags of property crime. The unit of observation is a jurisdiction-week. All crime rates are computed by dividing the actual number of crimes during a week by the average number of weekly crimes within the jurisdiction. Other covariates include average temperature and total precipitation in the current period, jurisdiction-year fixed effects, jurisdiction-specific $4^{\text {th }}$ order polynomials in day-of-year, and fixed effects for month. Standard errors in parenthesis are clustered at the state*year*month level. Observations are weighted by the mean number of all crimes within the jurisdiction. 
Figure 4: Heat Waves and Violent Crime

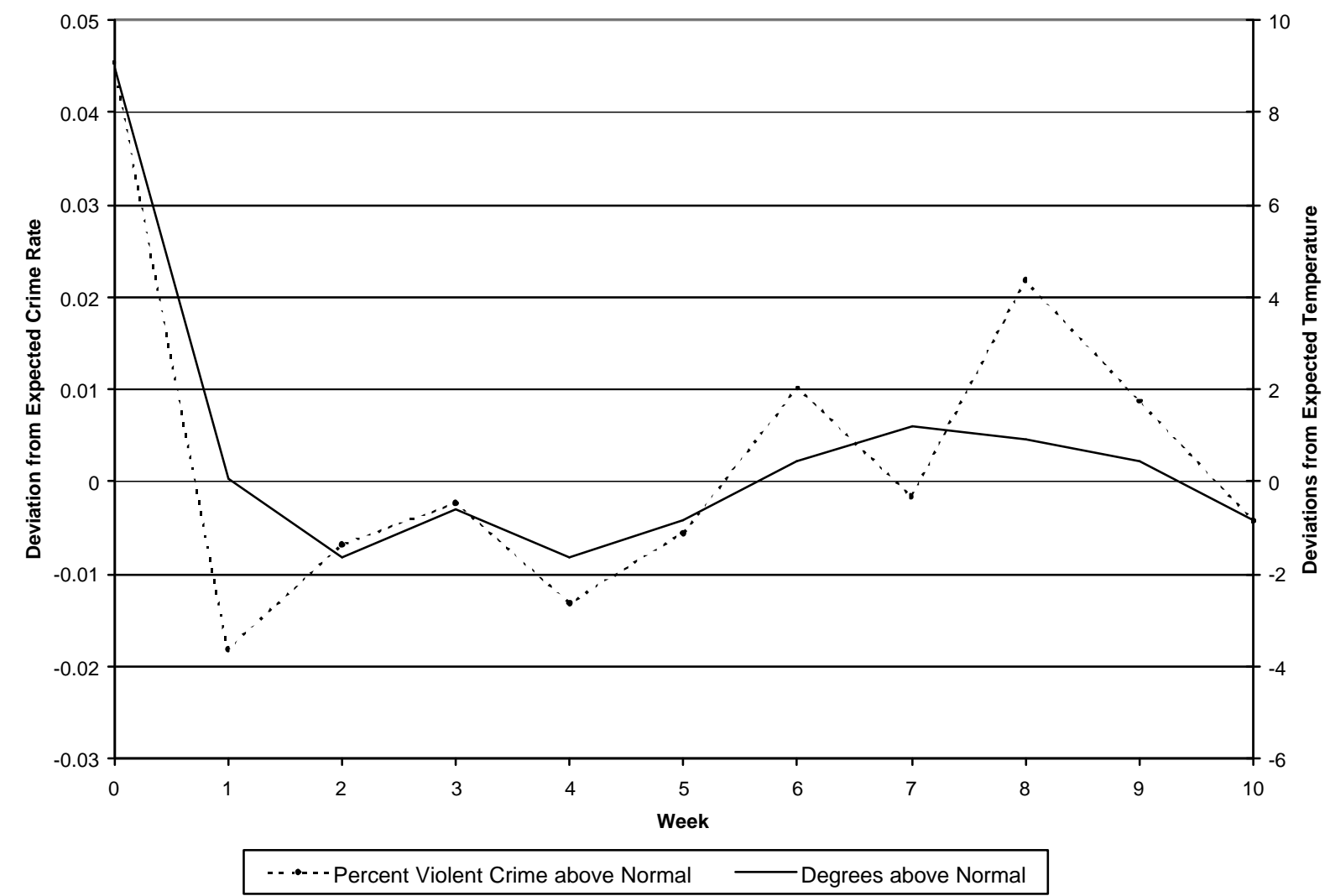

Notes: For this figure, we regressed temperature on month fixed effects, jurisdiction*year fixed effects, and jurisdiction-specific fourth order polynomials in day of year. We included periods in our sample in which the temperature in week 0 was more than 6 degrees Fahrenheit above predicted (using our controls) and the temperature in week 1 was within 3 degrees of predicted. For each week, we show the average temperature residual—weighting each jurisdiction by the average number of crimes committed during a week. We also show the average violent crime residual, which is obtained by running a regressions with controls discussed above. 


\section{Figure 5: Heat Waves and Property Crime}

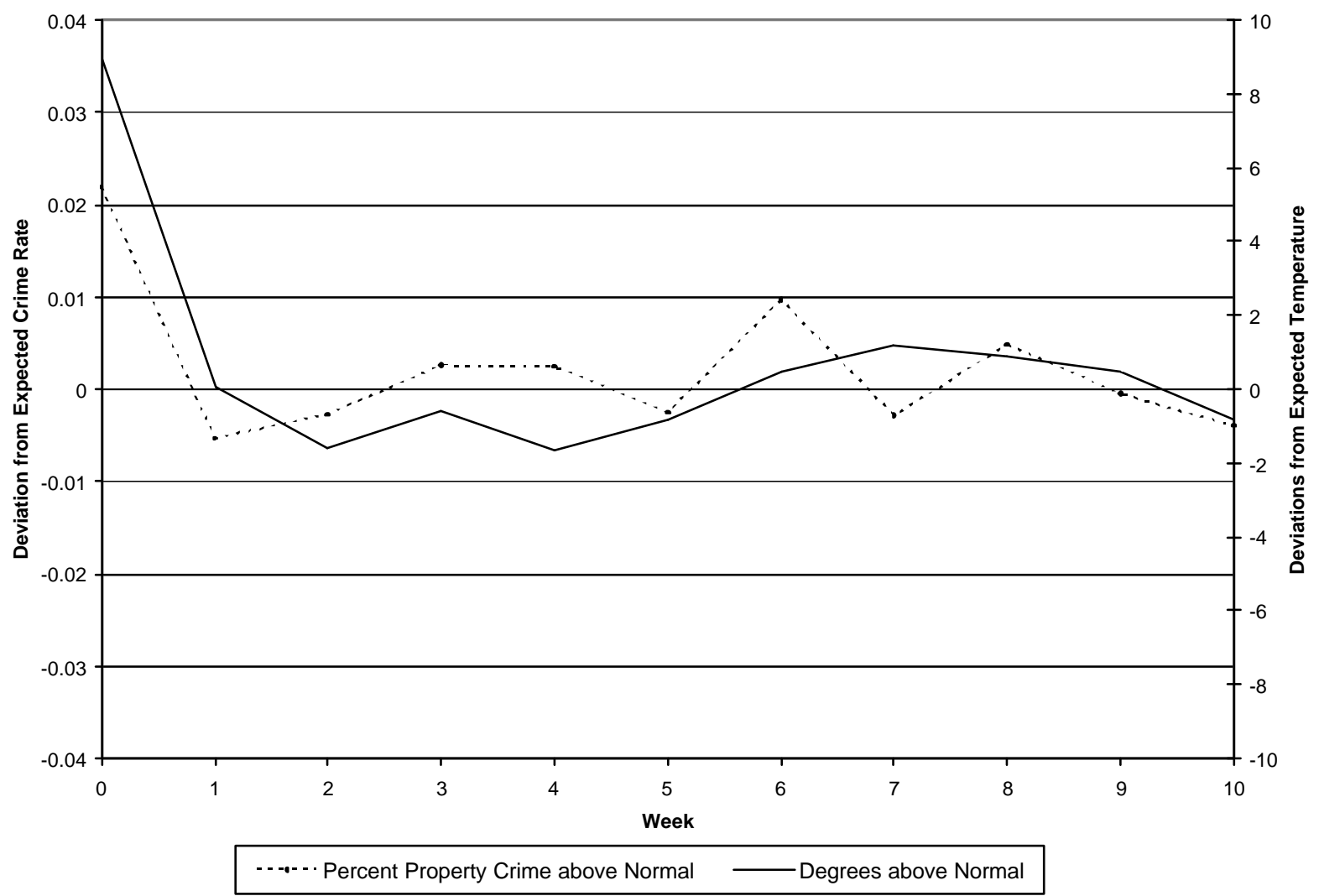

Notes: For this figure, we regressed temperature on month fixed effects, jurisdiction*year fixed effects, and jurisdiction-specific fourth order polynomials in day of year. We included periods in our sample in which the temperature in week 0 was more than 6 degrees Fahrenheit above predicted (using our controls) and the temperature in week 1 was within 3 degrees of predicted. For each week, we show the average temperature residual—weighting each jurisdiction by the average number of crimes committed during a week. We also show the average property crime residual, which is obtained by running a regressions with controls discussed above. 
Figure 6: IV Estimates of the Relationship between Current and Lagged Violent Crime

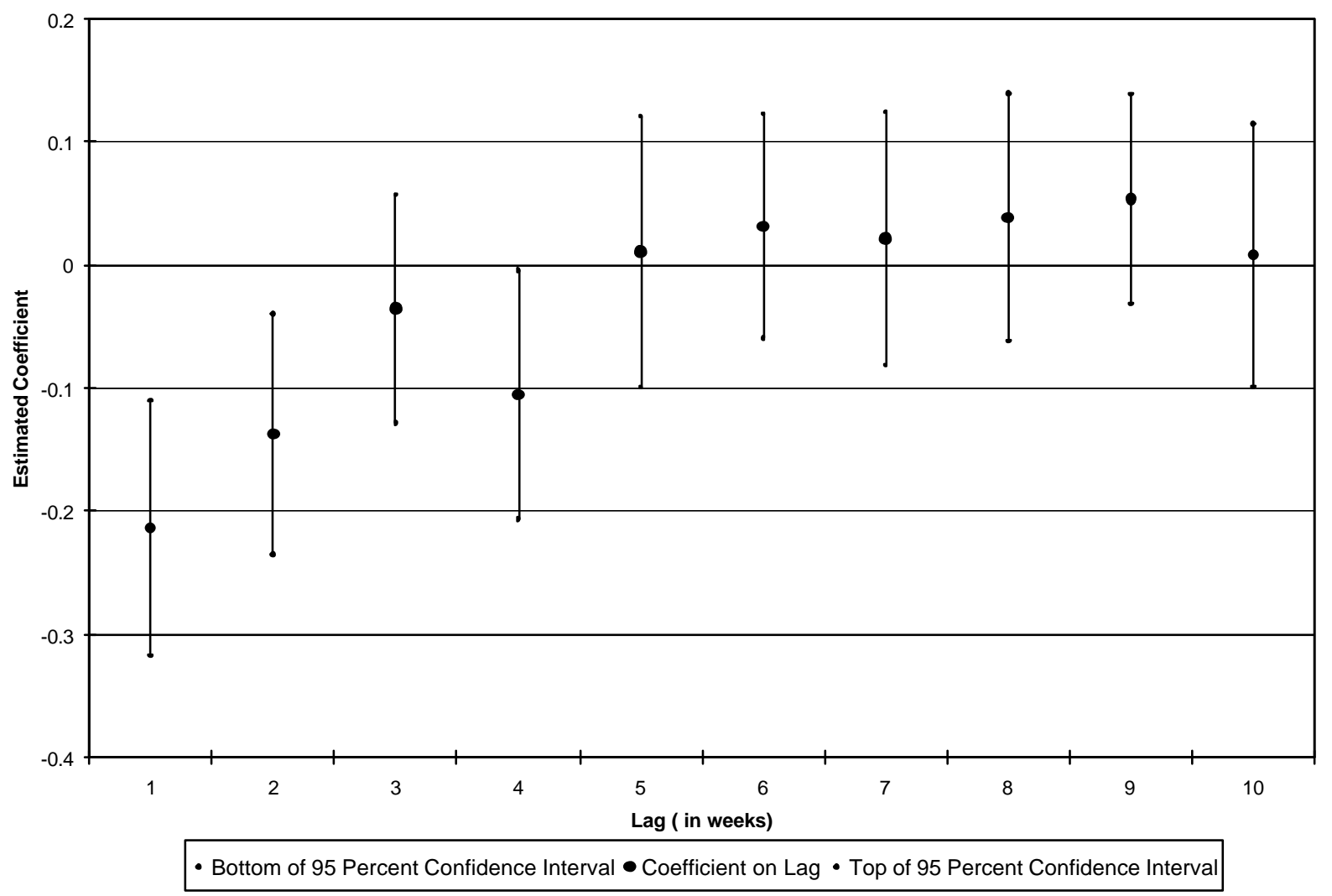

Notes: This figure shows the IV estimates from a regression of current violent crime on 10 lags of violent crime. The unit of observation is a jurisdiction-week. All crime rates are computed by dividing the actual number of crimes during a week by the average number of weekly crimes within the jurisdiction. Other covariates include average temperature and total precipitation in the current period, jurisdiction-year fixed effects, jurisdiction-specific $4^{\text {th }}$ order polynomials in day-of-year, and fixed effects for month. Lagged property crime is instrumented using lagged average temperature and total precipitation. See the text for more details. Standard errors in parenthesis are clustered at the state*year*month level. Observations are weighted by the mean number of all crimes within the jurisdiction. 
Figure 7: IV Estimates of the Relationship between Current and Lagged Property Crime

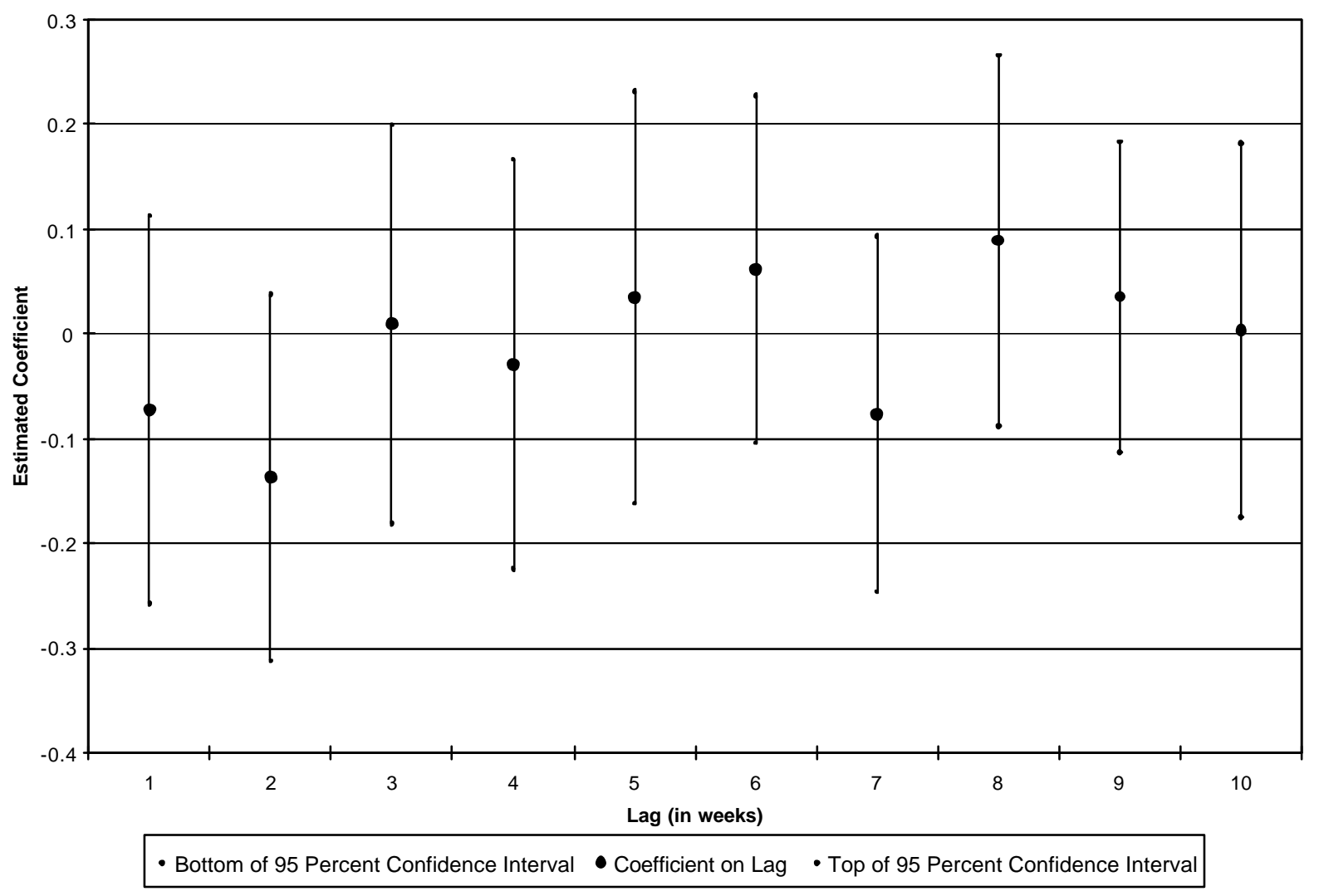

Notes: This figure shows the IV estimates from a regression of current property crime on 10 lags of property crime. The unit of observation is a jurisdiction-week. All crime rates are computed by dividing the actual number of crimes during a week by the average number of weekly crimes within the jurisdiction. Other covariates include average temperature and total precipitation in the current period, jurisdiction-year fixed effects, jurisdiction-specific $4^{\text {th }}$ order polynomials in day-of-year, and fixed effects for month. Lagged property crime is instrumented using lagged average temperature and total precipitation. See the text for more details. Standard errors in parenthesis are clustered at the state*year*month level. Observations are weighted by the mean number of all crimes within the 